\title{
WestVirginiaUniversity
}

THE RESEARCH REPOSITORY @ WVU

Graduate Theses, Dissertations, and Problem Reports

2017

\section{Chronic Illness and Physicians' Referrals to Psychologists: A Pilot Study}

Nicole O'Barto-Trainer

Follow this and additional works at: https://researchrepository.wvu.edu/etd

\section{Recommended Citation}

O'Barto-Trainer, Nicole, "Chronic Illness and Physicians' Referrals to Psychologists: A Pilot Study" (2017). Graduate Theses, Dissertations, and Problem Reports. 6336.

https://researchrepository.wvu.edu/etd/6336

This Dissertation is protected by copyright and/or related rights. It has been brought to you by the The Research Repository @ WVU with permission from the rights-holder(s). You are free to use this Dissertation in any way that is permitted by the copyright and related rights legislation that applies to your use. For other uses you must obtain permission from the rights-holder(s) directly, unless additional rights are indicated by a Creative Commons license in the record and/ or on the work itself. This Dissertation has been accepted for inclusion in WVU Graduate Theses, Dissertations, and Problem Reports collection by an authorized administrator of The Research Repository @ WVU.

For more information, please contact researchrepository@mail.wvu.edu. 
Chronic Illness and Physicians' Referrals to Psychologists: A Pilot Study

Nicole O'Barto Trainer

Dissertation submitted to the College of Education and Human Services

at West Virginia University

in partial fulfillment of the requirements for the degree of

Doctor of Philosophy

In

Counseling Psychology

\author{
Margaret Glenn, Ed.D., Chair \\ James Bartee, Ph.D. \\ John Blake, Ph.D. \\ Jeffrey Daniels, Ph.D. \\ Melissa Olfert, Ph.D. \\ Catherine Yura, Ed.D
}

Morgantown, West Virginia

2017

Keywords: Chronic care; biopsychosocial theory; physician-patient relationship; collaborative care; chronic illness; depression; mental health

Copyright 2017 Nicole O'Barto Trainer 


\section{Abstract \\ Chronic Illness and Physicians' Referrals to Psychologists: A Pilot Study Nicole O'Barto Trainer}

The Chronic Care Model (CCM) is an evidenced based healthcare management system that encompasses a multidimensional approach to healthcare for the treatment of patients with chronic conditions. A component of this model is collaborative care. The tenets of the biopsychosocial model are central to collaborative care and evidenced-based health care interventions. These interventions provide integrated, patient-centered healthcare delivered by a multidisciplinary healthcare team. Recent research has indicated that psychologists can play a vital role on such teams. The purpose of this exploratory study was to subject the Biopsychosocial Endorsement Questionnaire (BEQ) to preliminary statistical analysis and to test its effectiveness for predicting physician referrals to psychologists. Principal axis factoring was used to determine if subscales from the BEQ could be identified as predictor variables for use in subsequent analyses. Hierarchical regression analysis was used to determine the amount of variance in physician referrals to psychologists that could be accounted for by the BEQ subscales physician-patient relationship and collaborative care. Results of the analysis are that $18 \%$ of the variance in physician referrals could be accounted for by these two subscales, with the physicianpatient relationship subscale being the strongest predictor of physician referrals. This study was successful at providing a preliminary answer to the question of whether or not physicians might endorse the biopsychosocial conceptual framework. It also provides support for further refinement of the Biopsychosocial Endorsement Questionnaire (BEQ) and the inclusion of biopsychosocial principles in future research that seeks to explain the complex relationships of 
factors impacting physician-initiated collaborative behavior. Although an a priori analysis deemed the sample size appropriate for the primary regression analysis, the study may have been underpowered and unable to detect specific, independent contributions of variables. 


\section{Table of Contents}

Dissertation Abstract $\quad$ ii

Chapter 1: Introduction 1

$\begin{array}{ll}\text { Research Question } & 6\end{array}$

$\begin{array}{lr}\text { Chapter 2: Overview of Literature } & 6\end{array}$

$\begin{array}{ll}\text { Chronic Illness } & 7\end{array}$

$\begin{array}{lr}\text { Chronic Illness and Mental Health } & 9\end{array}$

$\begin{array}{lr}\text { Chronic Care Model } & 12\end{array}$

$\begin{array}{ll}\text { Collaborative Care } & 15\end{array}$

$\begin{array}{lr}\text { Provider and Patient Engagement } & 20\end{array}$

$\begin{array}{ll}\text { Collaborative Care Healthcare Interventions } & 21\end{array}$

$\begin{array}{ll}\text { Summary } & 32\end{array}$

Research Questions and Hypotheses $\quad 34$

Chapter 3: Methods 36

$\begin{array}{ll}\text { Design } & 36\end{array}$

$\begin{array}{ll}\text { Participants } & 37\end{array}$

$\begin{array}{ll}\text { Sample Characteristics } & 38\end{array}$

$\begin{array}{ll}\text { Measure } & 39\end{array}$

Development of the BEQ Questionnaire 40

Data Analysis $\quad 43$

$\begin{array}{ll}\text { Chapter 4: Results } & 46\end{array}$ 
$\begin{array}{ll}\text { Preliminary Statistical Analyses } & 46\end{array}$

$\begin{array}{ll}\text { Principal Axis Factor Analysis } & 47\end{array}$

$\begin{array}{ll}\text { Cronbach's Alpha } & 51\end{array}$

$\begin{array}{lr}\text { Correlational Analysis } & 51\end{array}$

Hierarchal Regression Analysis $\quad 53$

Chapter 5: Discussion $\quad 55$

$\begin{array}{ll}\text { Research Findings } & 55\end{array}$

$\begin{array}{ll}\text { Limitations } & 57\end{array}$

$\begin{array}{ll}\text { Recommandations } & 62\end{array}$

$\begin{array}{ll}\text { Conclusions } & 65\end{array}$

$\begin{array}{ll}\text { References } & 67\end{array}$

Appendix A: Recruitment Script $\quad 86$

Appendix B: Email Invitation to Participants $\quad 88$

$\begin{array}{ll}\text { Appendix C: Questionnaire } & 90\end{array}$

$\begin{array}{lr}\text { Appendix D : Table } 1 & 98\end{array}$

$\begin{array}{ll}\text { Appendix E : Table 2 } & 100\end{array}$ 


\section{Chapter 1}

\section{Background}

The healthcare system in the United States is, and has been, in a crisis. One population that is continually cited as significantly impacted by the quality of prevention and care are those with complex chronic healthcare conditions. These individuals include those living with chronic health conditions such as heart disease, stroke, cancer, type 2 diabetes, obesity, and arthritis. These conditions are the leading causes of death and disability in the United States and also the costliest (U.S. Centers for Disease Control and Prevention (CDC), 2011). One of the reasons these conditions are considered complex is their association with coexisting mental health conditions such as depression and anxiety (Fise, Marsh, Nelson, Romley, \& Dash, 2017; Pinquart \& Shen, 2011a).

In 2005, the World Health Organization proposed that there could be "no health without mental health" (WHO, 2005). The Office of the U.S. Surgeon General included this assertion in a published report outlining the impact of mental health on the brain, and ultimately the body, in an attempt to underscore the importance of a shift in healthcare: from healthcare delivered in silos, with little or no attention paid to the interdependence of physical and mental health, to one that valued collaboration among providers and the integration of services (Priester, Kane, \& Totten, 2005). These changes in the conceptualization of health and disease, as well as healthcare reform, represent an opportunity for psychologists to establish themselves as vital providers of care within evidence-based healthcare practices. If psychologists wish to establish themselves as preferred providers in integrative models of care, it will be important for them to develop collaborative relationships with primary care professionals (Holleman et al., 2004). 
Purpose statement. The purpose of this study is to develop an instrument that can be used to learn more about primary care physicians' attitudes towards a biopsychosocial approach to the treatment of patients with chronic illnesses. This instrument can then be used by psychologists interested in developing collaborative relationships with primary care physicians in their community. A secondary aim is to pilot the instruments effectiveness for predicting physician initiated collaborative behavior with psychologists.

The role of the biopsychosocial approach. According to the Chronic Care Model (CCM), primary care healthcare is a biopsychosocial endeavor rather than a biomedical one (Bluestein \& Cubic, 2009; Salci, Schlindwein, Meirelles, \& Vieira da Silva, 2017); central to this is an awareness of the patient's perspective at the starting point and during treatment plan development (Van Dongen, 2016). Successful collaboration among providers of healthcare involves the development of relationships with key specialist groups and interprofessional communication is crucial (Roberge et al., 2016).

At the center of the relationship between physician and psychologist may be the theoretical model focusing on biological aspects that influence health along with the psychological changes, thoughts, emotions, and behaviors, as well as social issues that confound the care scenario. The traditional biomedical model of healthcare excluded psychological, social, and environmental factors when attempting to understand a disease or disorder. It was derived solely from the germ theory of disease and has prevailed for more than a hundred years (McDaniel \& DeGruy, 2014). However, the current state of health in the United States suggests that the biomedical model alone has not adequately addressed today's healthcare challenges.

These challenges include the fact that chronic health conditions and the associated complications are now responsible for the highest rates of mortality and disability in the United 
States (CDC, 2011). The etiology and course of chronic illnesses falls outside the explanatory power of the biomedical model (McDaniel \& DeGruy, 2014). Even mental health conditions could not be explained within this conceptualization of disease unless it was done so strictly in a biological context (McDaniel \& DeGruy, 2014).

Psychiatrist George Engel (1977) provided an alternative to the biomedical model. His biopsychosocial model conceptualizes people as a whole, integrating their biology, psychology, behavior, and social environment into one holistic discussion. The primary difference between the biomedical model and the biopsychosocial model is explicit in the titles, the inclusion of psychological and social factors. These factors are the same health determinants that play a role in the onset and management of many chronic diseases (Jaini \& Lee, 2015). Treatment based on the biopsychosocial model is considered essential for patients with chronic diseases. The theoretical viewpoints are central to collaborative and integrated care (Collins et al., 2010). However, the biopsychosocial model is poorly embedded into the primary care system. The operationalization of biopsychosocial principles depends primarily on the knowledge and skills at the individual provider level rather than system-wide (van Dijk-de Vries et al., 2012). Despite the endorsement of this model by most medical professionals, it is not a common element of normal practice (Collins et al., 2010).

Healthcare reform. In an attempt to address this, the federal passage of the Accountable Care Act (ACA) in 2010 provided recommendations to test new models of healthcare delivery. Primary care models such as the Patient Centered Medical Home (PCMH) are an example (Katon \& Unutzer, 2013). These models have attempted to integrate primary care professionals with other healthcare providers into multidisciplinary clinics (McDaniel \& DeGruy, 2014). However, implementation has proven to be a major challenge, because of the required changes in 
the conceptualization of health and disease, and the inclusion of new roles for healthcare professionals (Nutting et al., 2011). One of those new roles involves the provision of mental health care as part of the collaborative intervention (Katon \& Unutzer, 2013), and how to operationalize the coordination of all of the parties into a system that will increase positive health outcomes and improved quality of life for patients (Bray, 2004; McDaniel \& LeRoux, 2006; Walker \& Collins, 2009).

A leading proposal for accomplishing this integration is to start with the primary and routine healthcare services. This task in and of itself will require a reinvention of the way team members traditionally operate, given that the majority of primary care professionals and mental health professionals work independently. However, research has indicated that physicians are open to partnerships in their efforts to address the mental health issues presented by their patients (McDonald et al., 2012; Miller-Matero, et al., 2016), indicating that they are often overwhelmed by the needs of these patients (Katon, 2011; Knowles et al., 2015) and are often uncertain of the appropriate intervention (Craven \& Bland, 2006).

There is information regarding the mechanics of collaboration in environments where physicians and psychologists are collaborating at some level. Their desire to learn more has led to an understanding of some of the continued barriers (Chong, Aslani, \& Chen, 2013; Kainz, 2002; Lawn, Delany, Sweet, Battersby, \& Skinner, 2015) as well as the knowledge that the burden for collaboration lies with the psychologist (Beehler \& Wray, 2012; Craven \& Bland, 2006; Denelsky, 1995). Initial evidence also revealed the need for a change in the conceptualization of health and disease, treatment and healing into a biopsychosocial model (Frankel, Quill, \& McDaniel, 2003; van Dijk-de Vries et al., 2012). What is still unclear is how 
to move into a coordinated system when physicians and psychologists are not in collaboration? What is the best predictor of collaborative behavior?

One predictor may be the primary care physicians' endorsement of the biopsychosocial model. I start by investigating their understanding of the principles of this model as it applies to the treatment of patients with chronic illnesses and whether or not they use this approach. Does this make a difference in their perspective of prioritizing psychological interventions and collaborating with mental health professionals? How aware are they of psychologists practicing in their communities and do they referral to those professionals? The goal of this study is to investigate these types of questions in order assist my colleagues in initiating collaborative relationships with primary care physicians in their communities, with the ultimate contribution being to the larger efforts within healthcare reform to improve the treatment of patients with chronic illnesses.

\section{Summary}

I start this investigation with an understanding from the literature that mental health care can have a positive effect on health outcomes of people living with chronic illnesses. Building on this understanding, it is apparent that increased efforts to coordinate care show promise for operationalizing this in the lives of primary care patients. In addition, there is evidence that this type of care is not occurring at a significant level with key members of the mental health care community, specifically psychologists. This exploratory study is designed to identify correlations that may serve to change this behavior. The study will investigate possible correlations between the variables of collaboration and referral with understanding of the biopsychosocial model of healthcare. The intention is to discover if there is a relationship between them. From this information, I can extrapolate data in the literature that may reveal 
opportunities to conduct future research into the limitations in the existing models of care and for expanded utilization of psychological services.

The biopsychosocial approach has been central to the conceptualization and delivery of a system of health care that is focused on collaboration between the fields of medicine and psychology to provide integrative care. Healthcare reform has placed an emphasis on the role biological, psychological, and social factors play in the conceptualization of health and disease, as well as their outcomes (Collins et al., 2010). Integrative interventions were deemed necessary to increase the chances of successful treatment of chronic illnesses, with collaboration among healthcare and mental health care providers an essential component (Gatchel \& Oordt, 2003; Katon, 2011). The prevalence of mental health diagnoses, particularly depression associated with chronic illnesses led to a particular focus on the interaction of primary care physicians and psychologists (Pinquart \& Shen, 2011a), interactions that may be influenced by perceptions or attitudes, awareness of the concepts and need for integrative care, and past experiences of the professionals. With this in mind, the current study attempted to identify the predictive value and the relationship between the biopsychosocial model and collaboration and referrals with psychologists. The following research question was posed: Is the implementation of the principles of biopsychosocial theory by primary care physicians a predictor of collaborative behavior with psychologists?

\section{Chapter 2. Literature Review}

Developing an approach to operationalize collaborative relationships between psychologists and primary care physicians requires knowledge of the theoretical underpinnings of the Chronic Care Model and the identification of barriers to the implementation of a collaborative care approach. Complex, chronic conditions require a team of healthcare 
professionals focused on the nuances of the conditions (Katon \& Unützer, 2013). There is a need for understanding the medical condition that is biological in nature and the role of psychological factors. There is also the need for behavior changes and long-term maintenance of healthy practices to ameliorate the medical condition. The variables are diverse as the number of people with chronic health conditions, conditions from cardiovascular events to diabetes and arthritis.

As a result, the healthcare system must address the variables with patient-centered care that includes a variety of healthcare professionals trained to address the presenting issues. The following provides more detail regarding these variables and how research and promising practices have addressed them.

\section{Chronic Health Conditions}

The healthcare burden in the U.S. stems from a short list of factors that place people at increased risk of developing a chronic health condition. The list includes tobacco use, excessive alcohol consumption, poor diet, lack of physical activity, uncontrolled blood pressure, and high cholesterol (Bauer, Briss, Goodman, \& Bowman, 2014). According to the West Virginia Health Statistics Center (2017), West Virginians engage in these behaviors at staggering rates. More than one fourth of West Virginia adults $(28.7 \%)$ participate in no leisure-time physical activity or exercise, which is the $5^{\text {th }}$ highest in the nation. The prevalence of obesity in West Virginia was $35.7 \%$, the second highest in the nation. And more than one fourth of adults currently smoke cigarettes $(26.7 \%)$, the second highest in the nation. Most of these conditions are also associated with multigenerational poverty, to include depression/mood affective disorders and mental/behavioral disorders (26\% and 22\% respectively) (Callander, Schofield, \& Shrestha, 2013). In order to effectively treat chronic illnesses and decrease the burden that chronic disease management presents to our healthcare system, the public health and healthcare systems must 
develop integrated strategies that bundle interventions to treat multiple risk factors

simultaneously, and go beyond health clinics by building communities that promote health rather than disease (Bauer et al., 2014). Clay Marsh, M.D., of West Virginia University Health Sciences Center, at the Future of Chronic Care Summit, [July 18, 2017; Washington, D.C.] referred to it as reknitting communities, focusing on elements that promote health and well being (Fise, Marsh, Nelson, Romley, \& Dash, 2017).

Those in healthcare practice are dealing with the effects of the increased incidence and high prevalence rates of chronic illnesses in the United States across the last four decades and will be doing so for the foreseeable future (Pinquart \& Shen, 2011a). The U.S. Centers for Disease Control and Prevention (CDC, 2011), reported that chronic health conditions represent the primary reason adults seek healthcare and associated treatment accounts for $86 \%$ of our nation's healthcare costs (CDC, 2011). The most commonly occurring conditions are heart disease, stroke, cancer, type 2 diabetes, and obesity. These are also the costliest and the most preventable (CDC, 2011). As of 2012, about half of all adults (about 117 million people) had one or more chronic health conditions (Ward, 2012). Seven out of ten deaths in 2010 were from chronic diseases, with heart disease and cancer accounting for nearly 48\% (CDC, 2013). According to the CDC (2012), 9.3\% of the population have diabetes and diabetes is the seventh leading cause of death. In the state of West Virginia, the prevalence of diabetes is $14.1 \%$, the $4^{\text {th }}$ highest in the nation (West Virginia Health Statistics Center, 2017). Moreover, diabetes is the leading cause of kidney failure and of new cases of blindness in adults. It is also the second leading cause of lower limb amputations (CDC, 2012).

Chronic illnesses are long-term health conditions that reduce the patient's daily functioning and vary in intensity over time. Some of the challenges faced by patients with 
chronic conditions are the development of self-management strategies, self-monitoring of health, uncertainty of diagnosis and treatment adjustments, and poor medication adherence (Lin et al., 2012). One of the challenges in treating these illnesses is recognizing the symptoms, as well as applying the appropriate interventions effectively. Factors to consider include choosing the appropriate healthcare system and identifying and developing an effective treatment strategy that includes the correct psychological intervention (Schulman-Green, et al., 2012).

Despite the significant resources allocated to the treatment of chronic illnesses, many patients with chronic illnesses have unfavorable health outcomes (Lin et al., 2012). Successful treatment requires healthcare management, a component of which is coordinated care. However, according to the Institute of Medicine (2012b), healthcare management is fragmented in our current system. Most patients with chronic illnesses received limited healthcare coordination from primary care physicians, and often seek help from various clinicians without any degree of collaborative care (Baron, 2010).

Chronic illness management is considered one of the core components of healthcare reform and is the goal of the Patient Centered Medical Home (PCMH) model (Katon \& Unutzer, 2013). The PCMH is designed to improve the quality of care provided to patients with chronic illnesses by maximizing access to care, continuity of care, and comprehensive care. In order to accomplish this, primary care healthcare is moving away from provider-centered models focused on the biological aspects of the patient's disease to more patient-centered biopsychosocial models that are characterized by a multidisciplinary team of providers focused on both the physical and psychosocial needs of the patient and their family (Johnson, 2013; Kazak, Nash, Hiroto, \& Kaslow, 2017).

\section{Chronic Health Conditions and Mental Health}


In order to fully appreciate the role of psychologists in chronic health care, it is imperative to understand the nature of the illnesses and the role of mental health in both the treatment and the disease. Chronic illness as well as the burden of the ongoing management of chronic illnesses increases the risk for psychological problems (Beacham et al., 2012; Pinquart \& Shen, 2011a; Roberge et al., 2016). The Epidemiologic Catchment Area Study conducted by Wells and colleagues resulting in findings that revealed $41 \%$ of patients with chronic illnesses developed psychiatric disorders such as anxiety, depression, and substance abuse (Wells, Golding, \& Burnam, 1988).

Patients with chronic medical illnesses were twice as likely to develop major depression as compared to other primary care patients. Specifically, primary care patients incurred a 5- to $10 \%$ tendency to develop depression, with an 18 - to $23 \%$ prevalence for patients with diabetes or coronary heart disease respectively (Pinquart \& Shen, 2011a). Possible explanations are that patients with chronic conditions are more likely to live sedentary lifestyles, feel isolated from peers, and deal with ongoing pain and fatigue, thus placing them at greater risk for depression (Herring, Puetz, O’Connor, \& Dishman, 2012; Pinquart \& Shen, 2011a). Additionally, comorbid depression has been associated with reduced adherence to treatment recommendations, increased health care utilization, and poor health outcomes (Herring et al., 2012). Moreover, when both physical and mental health disorders are present there is an increased risk for decreased functionality as well as disability (Katon et al., 2010; Von Korff et al., 2011).

Focusing on the link between diabetes and depression, the prevalence of clinical depression among patients with diabetes is twice that of the general population (Anderson et al., 2001; Bruce, 2005; Park, Katon \& Wolf, 2013). Diabetes shares certain metabolic features with depression and mental health disorders, and the long-term use of certain antidepressant 
medications may have implications for the development of type 2 diabetes (SAMSHA, 2013). In turn, when depression accompanies diabetes, studies have found higher rates of obesity, impaired functionality and quality of life, poor glycemic control, and decreased physical activity (de Groot et al., 2001; Lustman et al., 2000).

There is a bidirectional direct relationship between chronic illnesses and depression. The health risk behaviors associated with depression also represent an increased risk for the development of chronic illnesses. In the same way, the complications - as well as biological changes associated with chronic illnesses - also increase the tendency to develop depressive symptoms (Beacham et al., 2012; Katon, 2011). Furthermore, comorbid depression has been associated with an increase in the number, frequency, and severity of medical symptoms, poor adherence to medication regimens, and increasing morbidity and mortality rates among patients with chronic medical conditions (Katon, 2011).

Historically, healthcare of patients with chronic disease focused on interventions for single conditions while coexisting issues, particularly symptoms of mental health disorders, were not considered. However, research in this area has found that it is essential to embrace a biopsychosocial-oriented, patient-centered, team-based intervention to help these patients develop effective self-monitoring, improve medication adherence, and make timely treatment adjustments (Jacques et al., 2016; Lin et al., 2012). In summary, to ensure positive outcomes among patients with chronic physical and psychological illnesses, increased collaborative care and care coordination within the healthcare system is required (Von Korff et al., 2011). The Chronic Care Model (CCM) drives collaborative care. 


\section{Chronic Care Model}

The implementation of the Affordable Care Act of 2010 included health system reforms that can address the deficiencies in the provision of healthcare in the United States (Shields, Patel, Manning, \& Sacks, 2011). One of these initiatives is adoption of new healthcare models such as the chronic care model (CCM), an evidence-based approach to the treatment of chronic illnesses derived from principles found in a biopsychosocial theoretical orientation of clinical care. In the CCM, patients interact with a proactive multidisciplinary team of health professionals. Healthcare practices operating from the CCM perspective achieve positive results due to their ability to provide support to patients in decision-making, delivery of a system designed for high quality care, implementation of systems that promote information sharing among team members, monitoring effectiveness of care for patients, identification of intervention specific to the needs of patients, and improved supports for patient self-management of their health conditions (Bowen et al., 2010); all of this results in better health outcomes and satisfaction for both clinicians and patients (Bowen et al., 2010).

CCM components. In order to better illustrate the CCM, its six interrelated components for system change are introduced and defined: (1) health systems that provide safe, quality care, (2) self-management support, (3) decision support, (4) delivery system design, (5) clinical information systems, and (6) community resources (Stellefson, Dipnarine \& Stopka, 2013). A study of the effectiveness of this integrated framework for redesigning how healthcare practices indicated it appears to be supported as a model for redesign, as well as leading to improved care and health outcomes (Coleman, Austin, Brach \& Wagner, 2009).

Health system. The redesign of health systems promoted by the CCM represents a cultural change within the medical environment. It challenges leadership to create a culture that 
promotes high quality care (WHO, 2016). One operational concern is minimization breakdowns in communication and care coordination. Another is to develop agreements that promote data sharing with specialty groups in order to help patients navigate healthcare settings and providers more easily (Stellefson et al., 2013; Wagner, Austin, \& Von Korff, 1996).

Self-management support. In this model, the patient is central to the management of their condition(s). As a result, the CCM includes promoting opportunities for patients to learn to manage their health and health care (WHO, 2016). This would include facilitation of skills-based learning for the patient in order to successfully manage the cognitive, emotional, and behavioral aspects of their health conditions and thus maintain quality of life and increase positive health outcomes for themselves (Katon et al., 1995; WHO, 2016).

Decision support. Within the CCM patients are empowered with the responsibility of their own health and may need support in making healthcare decisions (WHO, 2016). This includes understanding and accessing evidence-based guidelines for directing their preferences in care; along with engagement in a healthcare system that is using evidence-based criteria for care.

Including psychologists on the health care team enhances the decision support component of the CCM, as mental health professionals are practiced in researching and implementing scientific models that address decision-making, many in the area of health choices (American Psychological Association, 2017). Psychologists have also been at the forefront of developing empirically based interventions responsive to specific individual, community, and population demographics (APA Presidential Task Force, 2008).

Delivery system design. The model promotes effective and efficient delivery of both clinical care and self-management support with an emphasis on health literacy and culturally sensitive health care practices (WHO, 2016). It encompasses the movement away from a 
reactive system into a more proactive system that stresses the importance of staying healthy. Psychologists could be vital contributors to conversations within the primary care model regarding culturally sensitive care and the development of wellness training programs (APA Presidential Task Force, 2008).

Clinical information systems. Facilitating effective and efficient care requires correct patient and population data being accessible to the health care team (WHO, 2016). This includes reporting of any improvement by patients or other changes to relevant healthcare providers.

Community. The CCM does not see health care stopping in the physician's office or medical center (WHO, 2016). The WHO, in their overview of integrative care models, listed strategies that include advocacy, facilitating patient access to community programming, and creating partnerships in the community to fill in the gaps of patient needs. All of these areas may lead to the need for psychologists. Within the CCM there are opportunities for psychologists to practice as facilitators of quality improvement, to work as team leaders, or as care coordinators invested in "whole-person care" and the reduction of fragmented healthcare (McDaniel \& DeGruy, 2014).

Coordination of care. The increasing demand for addressing mental health issues related to chronic disease requires an efficient approach to coordination of care because effective approaches to manage the healthcare of patients with chronic diseases requires both psychological and physical interventions (Fleury, Imboua, Aubé, \& Farand, 2012; Katon et al., 2010).

The first task in effective coordination of care is maintaining the patient's continuity of basic primary healthcare (O’Malley et al., 2010). Additionally, effective care coordination involves tracking referrals and consultations, and sharing information, coordinating healthcare 
results, and integrating the recommendations among the concerns (O'Malley et al., 2010). The exchange of information among the healthcare team is an essential task to perform and historically has been missing from our healthcare system, resulting in fragmented and inadequate healthcare (O’Malley et al., 2010). Care coordination enables the integration of services that are centered on the comprehensive needs of the family and the patient, such as the reduction of cost and the improvement of the experience of care, as well as better health outcomes (Turchi et al., 2014).

\section{Collaborative Care}

The CCM is an evidence-based healthcare management system that addresses the needs of people with chronic illnesses at the individual and community level (Thota et al., 2012). Collaborative care models derived from the CCM are grounded in biopsychosocial theory, and involve physical and psychological interventions delivered by a multidisciplinary healthcare team. Goals of collaborative care interventions include improved screening and diagnosis, increased patient satisfaction, improved self-management skills, and better overall health outcomes (Thota et al., 2012), all of which require a multidisciplinary team of providers and degrees of collaboration and care coordination.

The Patient Centered Medical Home (PCMH) is an example of this. Within the PCMH, the primary care physician (PCP) leads a team that includes physician assistants, office staff, advanced nurse practitioners, behavioral health specialists, care managers, pharmacists, and dieticians. This primary care team works collaboratively, focusing on the whole-person approach, which addresses the psychological, biological, and social health of patients. In such a healthcare system, primary care providers are responsible for coordination of care involving specialist groups including nurses and psychologists. 
Role of primary care physicians in collaborative care. Primary care physicians are responsible for care coordination within the healthcare system and among its providers because they are the point of entry for the patient into the system (Nash, McKay, Vogel, \& Masters, 2012). Therefore, PCPs should ensure that a referral system exists within their respective healthcare setting and identify the member responsible for securing the referrals, develop relationships with specialist groups in their community, and provide strong support in the whole process (Arena et al., 2012).

According to Arena et al. (2012), PCPs should provide support to the other healthcare professionals involved in the treatment team. In addition, the PCP's interactions with patients, their families, and other caregivers require that they understand the importance of every component of the healthcare intervention. Consequently, Arena et al. suggested that a physicianendorsed referral system resulted in higher rates of intake and enrollment in the healthcare intervention.

Historically, primary care professionals have been the de facto mental health system in the United States, treating more than $60 \%$ of all mental health problems without the help of psychologists or any other mental health providers (Reiger, Goldberg, \& Taube, 1978). Factors that influence a PCP's decision to make a referral include perceived availability of services in their community, time required to make a referral, confidence in the efficacy of the services available, and the reputation of the provider (Knight, 2003). Furthermore, Cunningham (2009) added that the PCPs' confidence in managing psychiatric conditions and personal experience with the service are also factors influencing a PCPs decision to involve a psychologist. PCPs who have had a positive personal experience with psychotherapy, for example, are more likely to refer a patient to such services. Consequently, a mutual interest in collaboration and increased 
education regarding the value and efficacy of services provided by mental health providers is essential to improving the referral process that involves PCPs, psychologists, and other parts of the primary care team.

In a naturalistic, qualitative study of collaborative care for patients with co-morbid depression and physical health problems, Knowles (2013) found that a significant barrier to successful collaboration was practitioner mindset. The individual interest in collaborative care resulting in collaborative communication superseded the practice setting. The existing norms around the division between physical and mental health were upheld despite the integrated setting. In this study, neither the nurses or the mental health professionals found a shared patient mindset resulting in joint management of the case to be beneficial (Knowles, 2013). Under the current system, patients with behavioral disorders are not treated effectively in the provision of primary health care because of the gatekeeping of PCPs (Raggi, 2011).

Role of psychologists in collaborative care. Along with the PCP, the psychologist plays an important role in the team-based holistic approach to healthcare interventions for patients with chronic diseases. Nash et al. (2012) argued that psychologists who are skilled in behavioral healthcare could significantly affect the outcome of the interventions provided by the PCMH. In this approach, the psychologist is integrated into the PCMH and adapts to the setting (Nash et al., 2012). However, even though psychologists work as part of the primary care team, traditionally they have not been located in the same facility as the primary care professional (Hunter \& Goodie, 2010).

Nash et al. (2012) thought that this integration into primary care presents a challenge for the psychologist because of the cultural and operational variation in primary care compared to traditional mental health interventions. Primary care is provided to prevent the disease as well as 
its progression through managing the health risk and ongoing treatment of the illness. However, in the traditional treatment paradigm, psychologists focus more on treatment than on prevention and early detection. Primary care caters to a greater number of patients, thus restricting the amount of time the PCP can devote to each individual. In the behavioral healthcare realm, on the other hand, each patient receives a consultation session that lasts a minimum of 50 minutes (Nash et al., 2012). While PCPs develop close ties with their communities, psychologists spend less time establishing a presence within the community and providing services to the community. These are a few of the challenges faced by the psychologist in the integration with primary care. The recent healthcare reform has provided psychologists with an opportunity to integrate their work into primary care settings (Nash et al., 2012). Along with this, the Patient Protection and Affordable Care Act of 2010 has focused on the promotion of innovative approaches to primary healthcare, such as the concept of the medical home, in order to achieve better patient outcomes. Moreover, previous studies (Berenson et al., 2011; Epstein, Fiscella, Lesser, \& Stange, 2010) posited that the PCMH is a coordinated care model of healthcare delivery, characterized by team-based healthcare, a patient-centered approach, continuous healthcare, and a system-based approach. Furthermore, other studies (Croghan \& Brown, 2010; Hunter \& Goodie, 2010) hypothesized that the concept of the medical home increased the likelihood of the patient having access to behavioral health services. The role of behavioral health interventions in primary care is well documented (Croghan \& Brown, 2010). Despite this claim, Nash et al. (2012) argued that the prevalence of the utilization of behavioral health interventions in primary care was unrecognized. Furthermore, Nash et al. noted that addressing the behavioral difficulties experienced during primary healthcare interventions was found to improve health outcomes. 
Alternatively, a study by Franz et al. (2010) found that the relationship between PCPs and mental health specialists could create complications for patients receiving care. Poor communication, lack of feedback among the healthcare team, and lack of coordination were some of the problems experienced by primary care physicians when involving mental health specialists (Franz et al., 2010). Moreover, Franz et al. explained that medical records took time and effort to transfer, which contributed to greater amounts of miscommunication. It was also noted that PCPs experienced challenges with receiving timely written and verbal feedback from mental health specialists, making the referrals either unhelpful or too late for the ongoing intervention. While PCPs need more guidance in addressing psychological disorders brought on by chronic illnesses, they usually find it difficult to access. For instance, PCPs depended on psychiatrists to prescribe medications, which further limited timely treatment (Franz et al., 2010). Raggi (2011) added there has been an increasing demand for training psychologists to collaborate with PCPs in the primary care setting through postgraduate programs. According to Pisani, Berry, and Goldfarb (2005), under the traditional medical model there is a boundary between PCPs and psychologists. Raggi pointed out that collaboration between these two health professionals has been inconsistent and in some instances, resisted. Raggi added that PCPs providing mental health referrals receive no further information from the mental health professionals providing mental health care to their patients. The occurrence of such a condition gives rise to the inefficient primary health care provided and the decrease of mental health referrals from PCPs (Raggi, 2011).

As discussed above, traditionally trained psychologists may not be comfortable with the level of enterprising activity that may be necessary in order to become an integral part of the changes in conceptualization of health and disease, and the delivery of healthcare itself. 
Therefore, if there is merit in the many articles written that purport that psychologists need to be prepared to make themselves indispensable to primary care, and if there is a separate set of skills that are markers of success, those skills need to be discussed throughout the education and clinical training of psychologists.

\section{Provider and Patient Engagement}

While the benefits of a supervised intervention for chronic illnesses that includes referrals to other healthcare providers in order to provide a comprehensive intervention have been established, statistics show that participation among eligible patients is low. To address this concern, a concerted effort on the part of the members of the healthcare team to promote outpatient intervention, enrollment, and referral is required (Gravely-Witte et al., 2010). Specifically, there is poor participation in rural areas, populations with a lower economic status, females, minorities, and the elderly (Arena et al., 2012). Current models of collaborative care do not adequately address this problem because the majority of trials have taken place in urban integrated clinics or have relied on existing staff to address health-related concerns that exist outside their traditional primary care roles. There are several factors to consider when examining the lower rate of participation such as automation, and level of integration within the setting, as well as the relationship among providers and ancillary health facilities, with the latter being a focus of the proposed study.

According to collaborative care approaches, healthcare interventions should be comprehensive and should be specific to the needs of the patient. Additionally, members of the healthcare team have a responsibility to the patient, their family, and the community to inform patients of the available therapies that best fit the patient's condition (Arena et al., 2012). Historically, this has been a barrier to patient engagement in mental health treatment. Patients 
generally do not regard their physical symptoms as having any impact on their mental health (Knowles, 2015). Nurses, together with other allied health professionals, may improve the continuum of healthcare and may increase the rate of referral and participation if they adopt a collaborative care mindset and understand the role of mental health in chronic care (Arena et al., 2012). For this reason, the roles of the members of the multidisciplinary healthcare team need to be clearly defined. Because the process of defining these roles is ongoing, collaboratively minded psychologists interested in being part of the healthcare equation for patients with comorbid chronic illnesses have an opportunity to create a role for themselves that was previously unavailable to psychologists. Furthermore, the roles should be based on clinical training and expertise, and not based solely on accessibility and location (Knowles, 2015). Although accessibility has historically been a concern as it relates to mental health care and collaborative relationships between primary care providers and psychologists, better efforts need to be made to identify preferred providers within communities in order to facilitate greater degrees of collaboration and improved access to care for the level of evidence-based intervention that an individual's health merits (Cunningham, 2009; Fisher \& Dickinson, 2014).

The successful transformation of the healthcare system is dependent on how well clinicians can adapt to the necessary changes in the way they think about themselves, their relationships with patients, and other clinicians (Nutting et al., 2011). Moreover, clinicians should be aware of the long-term commitment they are making to their patients and families.

\section{Collaborative Care Healthcare Interventions}

In a landmark randomized-control trial of collaborative-care conducted in the United States by Katon (2004), 329 participants with comorbid type-2 diabetes and depression or dysthymia participated. Using the PHQ-9, a survey questionnaire designed to assess for 
symptoms of major depression (range $0-27$ ), participants with scores of 10 or higher (88\% specificity for major depression (Kroenke, Spitzer, \& Williams, 2001)) were assigned to the Pathways collaborative care intervention or treatment as usual. The Pathways intervention included enhanced education to strengthen self-management and antidepressant support. The intervention was led by a nurse who received a 1-week training on pharmacotherapy and an introduction to problem-solving methods. Treatment as usual involved the participant following up with their primary care physician for the treatment of either their diabetes or depression. The patients assigned to the Pathways intervention reported less severity in depressive symptoms over time, higher satisfaction with care, and improved quality of life. However, the enhanced quality of care outcomes of depression were not accompanied by significant decreases in the biophysical markers measured during the 12-month period (Katon, 2004).

Although this study supports collaborative care, it highlights the importance of a more robust intervention for lifestyle and behavior change in order to have an impact on physical health, behavior change, and sustainable improvements in mental health symptoms and diagnoses. Also, the study has limited generalizability to other regions, cultures, and ethnicities because it was conducted in one large health clinic in the Pacific Northwest. Lastly, there was an opportunity for a spillover effect given that the same primary care physicians were treating both the control and intervention groups. The physicians could have had improvements in their knowledge and skills in treating depression, which could have had an impact on the treatment-asusual group.

A separate trial conducted by Katon, Lin, Von Korff, Ciechanowski, Ludman, Young and McCulloch (2010) focused on determining whether coordinated care management of multiple conditions could improve disease control in patients with chronic diseases and depression. In this 
study, 214 participants were randomized to an intervention group that involved a medically supervised nurse working collaboratively with a primary care physician to control risk factors associated with multiple diseases or treatment as usual. Treatment as usual required a routine ambulatory visit with the primary care physician involved in the study. The nurses leading the intervention attended a 2-day training course on depression management, behavioral strategies, and glycemic, blood pressure, and lipid control. Depression treatment included support for pharmacotherapy and improved self-care (Katon et al., 2010).

Results of the study showed that patients provided with evidence-based healthcare management were more satisfied with their treatment than those who received usual care from their primary care providers (Katon et al., 2010). Specifically, nurses enhanced patient self-care through education about self-monitoring, goal-setting, behavioral activation, and problem solving, which resulted in improved medication adherence as compared to the control group. A significant finding of this study was that, in addition to becoming more effective at managing their chronic illness, patients in the intervention group also experienced changes in their physical health as measured by glucose levels, blood pressure, and cholesterol values (Katon et al., 2010). Katon et al. (2010) suggested improved patient outcomes may have been a result of care coordination and increased collaboration for both patients and the healthcare team. This is consistent with the literature, which asserts that in addition to working collaboratively as a healthcare team, the successful treatment of chronic illnesses requires providers to adopt a systematic approach that supports health and health behaviors in their patients, their families, and the community. Furthermore, the close supervision and case reviews provided by the physicians and nurses resulted in timely support for the primary care physician in adjusting medications to achieve positive outcomes. Limitations of the study included the absence of a control group that 
received the same number of healthcare visits and potential disparities in health at the outset between the intervention and control groups because of the inability to examine between group differences. Additionally, this study utilized experienced nurses who were considered highly skilled in this area, which could have implications for generalizability. Lastly, the primary care physicians were treating both groups, so there was the potential for spillover effect.

The intervention described above was more patient-centered and holistic, which may explain its greater overall effectiveness compared to the earlier study performed by the same group of researchers. The researchers make special mention of the degree of collaboration among the healthcare providers and the nurses and the patients. Furthermore, in addition to being trained in problem solving, the nurses were also given training in goal setting and behavioral strategies. This could have translated to a greater degree of behavioral activation on the part of the patients, which would have an impact on both depressive symptoms and physical health.

McGregor et al. (2011) conducted a TEAMcare intervention for chronic illnesses and depression. The TEAMcare intervention sought to improve on the series of randomized-control trials that studied the effects of enhanced treatment for depression in patients with uncontrolled diabetes and found that while depressive symptoms improved over time, control of diabetes and self-care activities remained unchanged (Ell et al., 2010; Katon et al., 2005; Williams et al., 2004). This study included 214 participants recruited from 14 primary care clinics in western Washington state. Participants were individuals with poor markers of disease control for either diabetes or coronary heart disease comorbid with depression as determined by a score of 10 or greater on the PHQ-9. Consistent with other studies, the TEAMcare nurses received a 2-day training course on depression management, motivational interviewing, behavioral activation, and problem solving, as well as additional information about glycemic, blood pressure, and lipid 
control (McGregor et al., 2011). In response to earlier trials that did not demonstrate significant changes in participants' physical health, the TEAMcare intervention included behavioral activation to motivate patients to increase social contacts and pleasurable activities, in the interest of improved self-management and ultimately physical health (McGregor et al., 2011).

The nurses responsible for providing the enhanced-treatment-for-depression component of the TEAMcare intervention expressed a lack of confidence in their ability to carry out the motivational interviewing and behavioral activation strategies. Additionally, during weekly caseload reviews the nurses reported concerns about managing the multitude of symptoms associated with the diagnosis of depression presented by the patients and challenges with remaining optimistic with the patients who had the most treatment-resistant depression. As a result, the study concluded that although the TEAMcare intervention has the capacity to be effective for patients with uncontrolled diabetes and coronary heart disease comorbid with depression, it may be better suited to people with poorly controlled diabetes and heart disease and no coexisting depression (McGregor et al., 2011).

Another TEAMcare randomized control trial conducted in 14 primary care clinics in Washington State sought to achieve better outcomes for diabetes or coronary heart disease and depression by introducing the collaborative care management program (Lin et al., 2012). In this study, 214 participants with poorly controlled diabetes or coronary heart disease coexisting with depression as determined by a score greater than or equal to 10 on the PHQ- 9 were assigned to either the TEAMcare program or treatment as usual. The goal of the nurse-led intervention in this case was enhancing patient self-management, responsiveness and continuity of care, systematic follow up, and working collaboratively with physicians. The study was the first to focus on the impact of modifiable physician and patient behaviors for improved clinical 
outcomes. Although the study utilized the TEAMcare intervention, its focus was less on improving depression treatment as a means of improving overall health outcomes and instead examined adjustments to medical treatments more closely. The study may have limited generalizability because the patients were considered highly complex (Lin et al., 2012).

Another collaborative care randomized-control trial by Coventry and colleagues (2015) sought to examine the effectiveness of a collaborative intervention for patients with depression and long-term physical conditions by integrating a low-intensity psychological intervention within the context of primary care. Patients who received collaborative care were provided up to eight sessions of psychological care by one of 18 trained mental health providers participating in the study. All of the providers were employed by the agency Improving Access to Psychological Therapies; 12 of them were women and they had a mean of 3.9 years of experience. Participants were given the choice between cognitive or behavioral treatments. To better achieve integrated care, two sessions were delivered jointly with the primary care nurse. Primary care physicians and nurses provided usual care. Consistent with previous studies, patients in the intervention group experienced a decrease in depressive symptoms, were more satisfied with their care and felt they were more capable self-managers because of the intervention. However, there were no differences reported between the groups related to overall self-efficacy, quality of life, disability, and social support (Coventry et al., 2015). One limitation of this study is that it remains unknown if the benefits of the intervention extended beyond the 4-month period measured. In addition, there was the potential for assessment bias given that all outcome data were collected face-to-face at follow up and the researchers may have been aware of treatment allocations among the participants. Finally, this study was limited by its emphasis on the treatment of depression and the absence of any information collected related to physical health. In this way, 
its value as a collaborative care intervention is limited given that the very definition of collaborative care involves the treatment of both physical and mental health.

Although the body of research reviewed shows that a collaborative intervention that includes a team-based approach may be a more effective than the traditional ambulatory primary care visit, the current body of research explored undermines the treatment of depression and the training necessary in order to effectively assess and treat depression, ignores several aspects of the etiology of depression including cultural aspects, and does not easily generalize to rural communities where integrated multidisciplinary clinics may not be available.

Collaborative care models are driven by evidence-based healthcare; however, it is questionable whether current interventions for patients with depression and chronic illnesses provide a psychotherapy intervention for the depressive symptoms identified that is equivalent to evidence-based psychotherapy models (Bridges et al., 2015). In all but one of the studies explored, the psychological intervention for the depressive symptoms identified was largely psychosocial and psychoeducational. Furthermore, the design of the enhanced treatment for depression is focused largely on symptoms of depression that are associated with management of the chronic illnesses. None of the studies attempted to differentiate between patients who had a history of depression and had depressive episodes that occurred prior to or independent of the development of a chronic illness. Taking into consideration the context of which the depression occurred would be essential for encouraging the patient to participate in the most appropriate intervention. The enhanced treatment for depression interventions developed may be considered an adequate dose of a psychological intervention if the depression identified in the patient is directly related to the diagnosis of a chronic illness and represents the initial psychological burden of developing effective self-management strategies, or offsetting the diseases' negative 
effects on quality of life. It may not be an adequate dose for a patient who has a family and/or personal history of depression, and has had prior depressive episodes (Bridges et al., 2015).

Additionally, the research on patients with chronic illnesses and comorbid depression indicates that when depression occurs prior to or because of the diagnosis of a chronic illness, these patients are at a greater risk for disability and mortality, suggesting that they may require a more robust psychological intervention (Katon, 2011). Furthermore, although most of the studies cited improvements in depressive symptoms over time, none of the studies took into consideration the chronic nature of depression, the rates of recidivism, and the importance of establishing support at the familial and community level for participants prior to the conclusion of the study (Bridges et al., 2015). Although some of the studies identified maintenance strategies once patients met initial goals related to self-management and physical health markers, it is questionable whether or not it was sufficient. Chronic illness management is a continually shifting process that involves the complex interaction between the person, their illness, and their life context (Katon, 2011). That said, it would seem that a single dose of a psychological intervention delivered within the context of a primary care setting may not be adequate. This reinforces the significance of retaining the strengths of traditional biopsychosocial psychotherapy, including the importance of the therapeutic relationship and an orientation toward a positive expectancy of change (Barlow, 2004). All but one of the studies that utilized nurses as the care managers responsible for providing the psychological treatment to address the depressive symptoms identified, and those nurses received minimal training in depression, psychopharmacology, and behavior modification. In fact, when they were asked about their levels of confidence in treating the depressive symptoms identified in their patients they reported feeling ill equipped to manage the depressive symptoms and that treating depression required a 
different skill set altogether (Knowles, 2015). The development of collaborative care models and the redefining of primary care is based on the belief that under the biomedical model mental health has been ignored in the context of chronic care and the treatment of chronic illness, resulting in poor health outcomes and the healthcare crisis in our country. Biopsychosocial theory and its associated holistic patient-centered models have been presented as an alternative. However, in of all the studies explored, the psychological and sociocultural componentshallmarks of biopsychosocial theory - were minimal. The one study that utilized trained mental health specialists to deliver the psychological intervention described the intervention as a lowintensity psychological intervention (Coventry, 2015). It would seem unlikely that the goals of healthcare reform related to providing holistic patient-centered healthcare based on the tenets of biopsychosocial theory that transforms individuals and communities in the interest of improved self-management could be met with such minimal interventions delivered by professionals only minimally trained in mental health.

Furthermore, if only the minimal training provided to the nurses responsible for leading these collaborative care trials was required in order to effectively treat complex patients with multimorbidities, then it would call into question the legitimacy of the fields of counseling, social work, and psychology. Professionals working in those disciplines undergo extensive training and supervision in order to be able to provide clinical services to individuals suffering from mental health concerns. In some respects, the collaborative care interventions reviewed have yet to break from the traditional Western medicine model and mindset that contributed to the creation of the problems they are being charged with solving.

Finally, all of the clinical trials have taken place in large urban primary care clinics, and none of the studies explored mentioned the cultural context or the role of culture in the design of 
the intervention or in the treatment planning process that occurred between the nurse and the patient. Collaborative care approaches have been found to be less effective and in some cases ineffective for patients from minority groups (Unützer et al., 2011). There is a substantial body of literature in the field of counseling psychology and health psychology that addresses the importance of understanding the cultural context of an individual's experience of their health (Landrine \& Klonoff, 1992). This is reinforced in biopsychosocial theory. Multiculturalism in this context addresses the significance of cultural values, customs, and belief systems as they relate to health and disease. Multicultural psychology asserts that effective treatment takes into account these cultural beliefs, patterns of communication, and behaviors, and incorporates them into treatment in order to increase treatment effectiveness (Anderson et al., 2007). Care that is culturally sensitive is vital, especially in mental health treatment where an individual's response to therapy can be moderated by nuances of language and cultural beliefs (Anderson et al., 2007). It remains to be seen if the collaborative care interventions explored can effectively translate to real-world settings where the mental health component may need to be more flexible.

Critical questions remain regarding collaborative care, the biopsychosocial model, and behavioral healthcare interventions. For example, what impact has the shift away from the biomedical model had on physicians' thinking and behavior? Specifically, have the biopsychosocial principles of understanding the patient's perspective and experience of their illness, integrating the psychological and social domains, fostering collaborative care, and attending to the physician-patient relationship permeated physicians' thinking to the degree necessary to have an impact on behaviors? Furthermore, have physicians assimilated the principles of the biopsychosocial aspects of collaborative care interventions or have they maintained a biomedical mindset while carrying out biopsychosocially oriented healthcare 
interventions (Frankel, Quill, \& McDaniel, 2003)? The proposed study is designed to offer a unique perspective on the relationship between primary care physicians' endorsement of the biopsychosocial approach to the treatment of patients with chronic illnesses and collaboration and referrals with psychologists.

All of the studies explored have taken place in large primary care clinics, where integration has been more readily attainable. However, integration does not equal collaboration and more detailed explorations have revealed that provider mindset does not automatically shift when an integrated setting is established (Knowles, 2013). Additionally, qualitative research that has looked into patient perception of integrated services hasn't always favored mental health services being delivered in primary care clinics. It has also raised questions related to provider competence, and the ability of these models to meet the needs of individuals from different cultures (Anderson et al., 2007; Knowles, 2013; 2015). Nevertheless, collaborative care has demonstrated a greater degree of effectiveness for treating patients with comorbid chronic illnesses than the traditional primary care visit, so healthcare providers should be responsive to establishing relationships with psychologists in their community in the interest of collaborative care.

The cited literature shows that collaborative healthcare includes experts from different disciplines, and in order to maximize the provision of health, a multidisciplinary team is necessary. With this team-based approach, more efficient healthcare for patients with chronic conditions which includes increased patient satisfaction, improved self-efficacy as it relates to self-management, and improved health outcomes is expected. Within this model, behavioral health is no longer an afterthought, and psychologists and other mental health providers have an opportunity to become vital members of that team. However, it is important to point out, as many 
leaders in the American Psychological Association have, that it is not required for psychologists to do this work, and if we don't other professionals (such as nurses) will take our place (Bray, 2011). Future psychologists need to be trained differently: they need to be trained as generalists and comfortable working with a broad range of health and mental health problems in a variety of settings (Bray, 2011). At the same time, psychologists may have to resist the healthcare system's attempt to assimilate and simplify the field of psychology and its theories, and the doctrine of the therapeutic relationship. Much of the literature written by professionals within the American Psychological Association has advised psychologists to embrace roles in primary care if they feel so inclined. However, absent from that literature is the discussion of the potential for psychologists to become essential collaborators and preferred providers if they take an active approach to educating the primary care professionals in their community.

\section{Summary}

The importance of collaboration among healthcare providers within the larger healthcare system regardless of sector has been accepted in modern healthcare systems and interventions. As a result, multidisciplinary healthcare teams are a necessity. Historically, the primary care physician has been the primary provider of the healthcare intervention, but many other stakeholders are involved such as nurses, psychologists, and other allied healthcare providers. The field of integrated healthcare represents an opportunity for psychologists to leverage their training and specialized skillset to make them just as crucial in the intervention equation. Psychologists need to be prepared to position themselves not only as experts in the assessment and treatment of mental disorders, but also as experts in human behavior and behavior change.

The review of selected literature highlighted the need for more integrated patientcentered models of healthcare and associated interventions designed to address chronic illness in 
the United States. The total patient population may be best served by interventions that represent the bidirectional relationship between chronic illnesses and mental health; tailoring efforts to addressing the effects of chronic illness on one's mental health as well as how mental health effects the trajectory of the care of chronic illnesses. The Chronic Care Model shows promise for revealing the need for coordinated care within a collaborative care mindset. The studies cited support the application of the model in addressing concerns regarding effective healthcare interventions for this population, yet they revealed limitations to current models, providing an opening for the proposed study.

Preparation for this research study required that I present an exploration of a multidisciplinary healthcare team, outlining individual professional roles within the structure as well as the historical context that led to the current dynamic between these providers. Taken together, all of this information highlights the importance of psychologists being proactive in developing a role for themselves during this movement in healthcare.

\section{The Current Study}

The biopsychosocial approach, a perspective within the developmental psychological approach to holistic care, has been central to the conceptualization and delivery of a system of health care that is focused on collaboration between the fields of medicine and psychology to provide holistic integrative care. The emphasis has been on the role biological, psychological, and social factors play in the conceptualization of health and disease, as well as their outcomes (Collins et al., 2010). Integrative interventions were deemed necessary to increase the chances of successful treatment of chronic illnesses, with collaboration among healthcare and mental health care providers an essential component (Gatchel \& Oordt, 2003; Katon, 2011). The prevalence of mental health diagnoses, particularly depression associated with chronic illnesses led to a 
particular focus on the interaction of primary care physicians and psychologists (Pinquart \& Shen, 2011a), interactions that may be influenced by perceptions or attitudes, awareness of the concepts and need for integrative care, as well as past experiences of the professionals. With this in mind, the current study attempted to identify the predictive value and the relationship between primary care physicians' endorsement of the biopsychosocial model and collaboration and referrals with psychologists. To focus the investigation, an overall research question was posed with two specific hypotheses to be tested.

\section{Research Question and Hypotheses}

Research question. Is the implementation of the principles of biopsychosocial theory by primary care physicians a predictor of collaborative behavior with psychologists?

Hypotheses. The following hypotheses were put forth for testing.

H1: A principal axis factor analysis (PAF) of the Biopsychosocial Endorsement Questionnaire (BEQ) will yield five subscales reflective of biopsychosocial theory for the treatment of patients with chronic illnesses.

H2: The predictor variables [derived from the hypothesized subscales of the BEQ] (physician/patient relationship, physician self-awareness, collaborative care, illness narrative, and inclusion of psychosocial factors) will account for statistically significant variance in the outcome variable (referrals to psychologists) [derived from physician responses to item 12 on the BEQ]. 


\section{Chapter 3: Methods}

This chapter provides the details of the research design, study procedures, sampling, participant characteristics, instrument development, and data analysis.

\section{Design}

Principal axis factor analysis (PAF) was used to ascertain the statistical properties of the Biopsychosocial Endorsement Questionnaire (BEQ) before proceeding with a quantitative descriptive design utilizing multiple regression to evaluate the BEQ as a predictor of physician referrals to psychologists. Specifically, hierarchical multiple regression was used to determine the unique contribution of physician-patient relationship and collaborative care (two subscales of the BEQ) on physician referrals to psychologists.

\section{Procedures}

Participants were recruited to the study via an email invitation distributed to all primary care physicians registered with the West Virginia State Medical Association. In an effort to increase the response rate, two email message reminders were sent to primary care physicians who had not opened the email invitation and had not responded. The first reminder was sent out one week after the initial email invitation and the second reminder was sent out one week later, and served as a final reminder and follow-up (Heppner et al., 2008).

The email invitation provided participants with a web link which redirected their browser to a website operated by Qualtrics, a privately held experience corporation that operates a contractual relationship with the university conducting this research. The software allows users to conduct online data collection and analysis via the web. Once participants entered the website they were provided written instructions and criteria for participation. The participants were 
informed that the questionnaire would take approximately ten minutes to complete. The instrument itself consisted of an introduction, pertinent definitions and a statement of informed consent. Participants were informed that the study was approved by the West Virginia University Institutional Review Board. Participants were also informed that participation was anonymous and once they started the survey, participation implied consent. There was no collection of any personal identifiers or code numbers that could have linked a participant to specific information from the survey. Additionally, Internet Protocol (IP) addresses were not collected and, specifically, the Qualtrics survey software feature related to the capability of the tool to identify location of the participants was turned off. They were also informed participation was voluntary and that they could discontinue at any time without penalty. The site informed them of the minimal risk, such as feelings of discomfort, associated with participation. Their responses were collected directly from respondent input into the online instrument.

\section{Participants}

The questionnaire was distributed by email invitation to 1,576 licensed primary care physicians in the state of West Virginia. A total of 91 physicians completed the questionnaire, representing a 5.77\% response rate. The response rate for online surveys according to the survey literature is $30 \%$, therefore this is an unusually low response rate and a limitation to the study. Twenty cases were removed prior to data analysis due to missing responses ( 8 respondents only completed the first few items of the survey; 12 respondents skipped multiple items throughout). The researcher attempted to replace these cases with the mean or median but after further exploration it was determined that due to the severity of the number of missing responses, it was not appropriate, leaving a final, usable sample size of 71 , which represents $4.5 \%$ of the initial target population. 


\section{Sample Characteristics}

The sample characteristics were determined via a demographics questionnaire which will be discussed later in this chapter in the measure section. Descriptive data for the participants are presented in Tables 1 and 2 (See Appendix A \& B). Of the respondents, 40 (56.3\%) identified as male; 31 (43.7) identified as female. Participants ranged in age from 24 to 69 years $(M=49.73$, $S D=12.93)$. Fifty (70.4\%) of the participants reported having the degree of Medical Doctor (M.D.); 21 (29.6\%) reported having a Doctor of Osteopathic Medicine (D.O.) degree. The number of years in practice as a primary care physician ranged from less than 1 to 40 ( $M=20.03$, $S D=12.38)$. The largest percentage of participants reported spending $40 \%-60 \%$ of their day treating patients with chronic illnesses $(n=21,29.6 \%)$; the next largest were those who reported spending $60-80 \%$ of their time addressing the needs of this population $(n=20 ; 28.2 \%)$. These statistics serve to validate my intent to gain the perspective of physicians who work in a clinical capacity and treat patients with chronic illnesses. Further analysis revealed that almost half of the total participants were not aware of a psychologist practicing in their community $(n=34,48.6 \%)$ and a little over half had referred a patient with a chronic illness to a psychologist $(n=40$, $56.3 \%)$. Of those that did make a referral to a psychologist the number of referrals ranged from 1 to $50(M=3.72, S D=7.52)$. A relatively small minority $15.5 \%(n=11)$ had engaged in informal collaboration with a psychologist in the past 6 months on behalf of a patient and 19.7\% $(n=14)$ had engaged in formal collaboration with a psychologist in the past 6 months. The number of informal collaborations ranged from 1 to $7(M=0.44, S D=1.26)$ and the number of formal collaborations ranged from 1 to $25(M=0.72, S D=3.11)$. The majority of participants did not have a psychologist on staff $(n=62,87.3 \%)$.

\section{Measures}


The outcome variable investigated in this study was the average number of physician referrals to psychologists and was derived from physician responses to item 12 "Please indicate the number of referrals you have made to a psychologist in the past 6 months" on the BEQ. The predictor variables were derived from the five major components of biopsychosocial theory for the treatment of chronic illnesses: (1) physician-patient relationship; (2) physician selfawareness; (3) collaborative care; (4) illness narrative; and (5) inclusion of psychosocial factors (Frankel, Quill, \& McDaniel, 2003; Sperry, 2006). After subjecting the BEQ to principal axis factoring the Collaborative Care, Physician-patient Relationship, and Inclusion of Psychosocial Factors comprise a three-factor solution that accounts for $58.35 \%$ of variance.

While a 3-factor solution accounted for $58.35 \%$ of the total variance, a two-factor solution was preferred because although the Inclusion of Psychosocial Factors subscale was statistically significant $(r=.144, p<.05)$, the $\mathrm{rsq}=0.020$, was considered too weak for inclusion in the final model $(p=.244)$. Therefore, it was not included in the subsequent hierarchical regression analysis. The two-factor solution accounted for $48.38 \%$ of the total variance, or nearly half. I felt this was sufficiently robust to proceed with the regression analysis utilizing this 2factor solution. The results of the principal axis factor analysis do not support the hypothesis of a five-factor solution and the implications of this will be explored later in the discussion.

\section{Demographic Questionnaire}

I developed the demographic questionnaire to obtain specific general socio-demographic and practice-related information relevant to my study (see Appendix E). Questions included: age, gender, years in practice as a primary care physician, type of degree, primary work setting, and percentage of day to day clinical work involving the treatment of patients with chronic illnesses. Collaborative behavior related questions included: availability of psychologist or other mental 
health professional on site, awareness of a practicing psychologist in the community with which they work, number of referrals made to a psychologist in the past 6 months, number of informal collaborations with a psychologist in the past 6 months, and number of formal collaborations with a psychologist in the past 6 months.

\section{Predictor Variables}

One challenge inherent in exploratory research is that appropriate instruments are often unavailable. Instruments that survey primary care physicians' attitudes towards collaboration with other healthcare professionals have been developed in previous research efforts (Chomienne et al., 2010; Gatchel \& Oordt, 2003; Grenier at al., 2008; Lee et al., 2012). However, an investigation of those identified in the literature reviewed indicates a lack of assessments specifically designed to measure primary care physicians' attitudes regarding biopsychosocial theory and its relationship to collaboration in implementing an integrative system of care for the treatment of chronic illnesses. Therefore, I developed the Biopsychosocial Endorsement Questionnaire (BEQ) and subjected it to preliminary validation in order to operationalize the outcome variable for the present study.

Development of the Biopsychosocial Endorsement Questionnaire. I developed the initial potential item pool for the BEQ according to process informed by guidance derived from DeVellis (2003) and Croker and Algina (1986). Broadly, development of the initial item pool involved (1) selection of an appropriate item format, (2) verification of feasibility of the item format for the intended evaluees, (3) identification of potential items through review of current biopsychosocial theory and chronic illness literature, (4) review of potential items for theoretical and practical appropriateness, accuracy, technical item construction flaws, grammar, readability, and offensiveness or bias by a panel of qualified experts (i.e., clinical psychologists, counseling 
psychologists, and primary care physicians), (5) administration of potential items to study participants, (6) subjection of response data to principal axis factoring.

Relevant literature on scale construction suggested using theory as a guide in terms of developing the conceptual pillars of operationalization of theory (DeVellis, 2003). Furthermore, examining theory helps to establish the parameters of the construct that the content of the scale is focused on (DeVellis, 2003). After a review of biopsychosocial theory, I determined that item generation would be based on the application of the biopsychosocial approach for the treatment of chronic illness. After a comprehensive review of that literature that revealed five common themes in the operationalization of the biopsychosocial model for the treatment of chronic illnesses, I generated items as part of the scale development process. A key strategy in item generation is to revisit the research questions frequently and ensure that the items reflect these and remain relevant (DeVellis, 2003). This part of the process required considerable pilot work to refine wording and content. Once the initial pool of items was generated those items were pilot tested. The pilot test involved three non-respondent healthcare professionals. These individuals were chosen based on their experience treating patients with chronic illnesses, familiarity with psychological interventions, and experience collaborating with mental health professionals. It should be noted that these professionals may have represented a biased part of the population for which this topic would be relevant because of their relationship to the researcher. Each of these individuals had interacted with me in some clinical capacity at some point in time during my career. I met with these professionals individually and ask them to say aloud what they were thinking while they were considering the questions. This process was recorded using the iPhone application iTalk. The purpose of the think-aloud was to aid in content validity, clarity, and rewording of double-barreled and redundant items before the administration 
of the final questionnaire (Patton, 2000). For example, one physician indicated that while reading the questions comprising the original inclusion of psychosocial factors section that they felt compelled to agree because of how the questions were worded. Another physician commented that he felt the questions were idealistic and that they should be modified in order to reflect both the biopsychosocial theory and "real" primary care practice. After the focus group, all the items were reviewed a final time to ensure that each item addressed a single issue, were consistent in terms of perspective, and were comprised of language would be familiar to the target respondent. The final BEQ is composed of 20 items (4 items per hypothesized component of the operationalization of the biopsychosocial theory for the treatment of chronic illness).

Physicians were provided with statements related to the treatment of patients with chronic illnesses from a biopsychosocial perspective and asked to indicate on a 4-point Likert-type scale (strongly agree, agree, disagree and strongly disagree) the extent to which they agreed or disagreed with the statements. In measures interested in participants' attitudes, the 4-point Likert scale has been preferred over a 5-point version, which includes a neutral option, because the absence of a neutral option forces the participant to ponder their position but also reveal their position in situations where they might otherwise try to hide it in a neutral option (Patton, 2000). The items are grouped to form five subscales labeled Physician/Patient Relationship, Physician Self-Awareness, Inclusion of Psychosocial Factors, Illness Narrative, and Collaborative Care. Some examples of items include "The quality of the physician-patient relationship forms the basis for healing" (Physician/Patient Relationship), "Sometimes it can be beneficial for a physician to express his or her own emotions to a patient” (Physician Self-Awareness), "Effective management of healthcare for patients with chronic illnesses requires psychological interventions" (Inclusion of Psychosocial), "Patients' perspectives on their chronic illnesses are a 
critical component of self-management in healthcare" (Illness Narrative), "The quality of the physician-patient relationship is a determining factor in the facilitation of collaborative care" (Collaborative Care).

\section{Data Analysis}

Data was exported to IBM-SPSS (23.0) for analysis. Data was analyzed using descriptive statistics, principal axis factor analysis and hierarchical regression to test the primary research hypothesis. Descriptive statistics were computed for all predictor and criterion variables to examine the shape of the distribution (normal, skewness, kurtosis), central tendency (mean, median, mode), and dispersion (range, variance, standard deviation). Frequencies, percentages, means, and standard deviations were used to summarize demographic characteristics and measured variables of participants. All data were screened for missing information, outliers (Mahalanobis distances), and multicollinearity. Tests of factor analysis assumptions, including measures of sampling adequacy were examined (Kaiser-Meyer-Olkin). Tests of regression assumptions, including normality (kurtosis and skewness), linearity, and homoscedasticity, were examined for both predictor and criterion variables. Cronbach's alpha was computed to estimate internal consistency of scores on the Biopsychosocial Endorsement Questionnaire (BEQ). Development of Biopsychosocial Endorsement Questionnaire: Principal Axis Factor Analysis

Principal Axis Factoring (PAF) was selected because the literature includes reports of PAF as a method that is effective toward factorial categorization of items for inclusion in instrument subscales, when the subscales are hypothesized to correspond to constructs represented in theoretical models (e.g., Bedregal, O'Connell, \& Davidson, 2003). There is no consensus in the literature determining the appropriate sample size for exploratory factor analysis procedures such as PAF. However, similar research efforts have indicated that 100 cases is ideal to conduct an 
adequately powered factor analysis (Kass \& Tinsley, 1979; Nunnally, 1978). This is a limitation to the PAF performed in this study. The Kaiser-Meyer-Olkin (KMO) measure indicated sampling adequacy of 0.77 (greater than 0.50) and Bartlett's test of sphericity $(\chi 2=785.331$, df $=190, p$ $<.001)$ indicated that proceeding with the factor analysis was appropriate. Principal axis factoring was used to derive subscales from the BEQ that could be identified as predictor variables for use in the subsequent hierarchial regression analysis.

Sample size. An a priori analysis was conducted for the total $R^{2}$ value for a multiple regression analysis with two predictor variables using $G^{*} P O W E R$, a software application used to compute statistical power analyses for this type of study (Faul, Erdfelder, Lang \& Buchner, 2007). The computation used the following to determine the sample size: an alpha level of 0.05 , a power of 0.80 , and a medium effect size $\left(f^{2}=.15\right)$, using two predictor variables. The resulting recommendation was that a sample size of 68 would be sufficient. The final sample size after removing case with missing data that could not be replaced with the median or mean was 71 .

Regression analyses. Regression analysis is a method appropriate for examining the predictive power of variables and the contribution of each predictor variable with the criterion variable (Field, 2005). This set of statistical procedures has been popular in social sciences and counseling research. More specifically, its theory testing functionality and subsequent contribution to moving from theory to applied practice is particularly useful (Hoyt et al., 2008).

Hierarchical regression analyses. Hierarchical regression analysis (HRA) was used to determine the correlation of each predictor (subscales of the BEQ after subjected to PAF [physician-patient relationship and collaborative care]) and to determine the unique contribution and predictive ability of each predictor variable to the variance of the criterion variable (physician referrals to psychologists [average of physician responses to item 12 on the BEQ 
$(M=3.72, S D=7.52)])$. HRA is particularly beneficial when there is more than one predictor variable measuring a construct as in this study (Hoyt et al., 2008), because the change in $R^{2}\left(\Delta R^{2}\right)$ shows the combined contributions of the set of predictor variables in the same construct in explaining variance in the criterion variable, while $s r^{2}$ indicates the unique variance shared by the specific predictor variable.

A predetermined order of the predictor variables was entered into the regression model based on the results of the principal axis factor analysis. In this study, hierarchical multiple regression analysis was used to examine the relationships between the BEQ subscales and physician referrals to psychologists. Each of predictor variables were entered into the regression model and assessed in terms of what they added to the equation at their own point of entry (Tabachnick \& Fidell, 2001). The significance was set at alpha $=.05$. 


\section{Chapter 4: Results}

The purpose of this exploratory study was to subject the Biopsychosocial Endorsement Questionnaire (BEQ) to preliminary validation statistical analysis and pilot its effectiveness for predicting physician initiated referrals to psychologists. The BEQ was subjected to principal axis factoring in order to identify a potential underlying structure. Hierarchical regression analysis was used to determine the amount of variance in physician initiated referrals to psychologists that could be accounted for by two subscales of the BEQ following principal axis factor analysis (physician-patient relationship and collaborative care). This chapter describes the results of the statistical analyses used to evaluate the research question.

\section{Preliminary Data Screening and Analysis}

Data for all predictor and criterion variables were screened IBM-SPSS (23.0) for accuracy, data entry, multivariate outliers, and normality. Frequency tables were used to identify cases in which data had been entered in error. The presence of multicollinearity was assessed by examining the variance inflation factors (VIF) and tolerance. None of the VIF values exceeded 10 for any variables in the analyses (range, 1.02 to 4.17 ), and none of the tolerance values were less than .10 (range .24 to .98 ), suggesting that there is no multicollinearity in the data and that no large changes in coefficient would result from adding or deleting variables from the dataset. With the use of 2 predictors and $p<.05$ criterion for Mahalanobis distance, three outliers were deleted from the hierarchical multiple regression analysis, resulting in a sample size of 68 . The final sample size was consistent with the recommendation of 68 from the $\mathrm{G}^{*}$ Power analysis. Histograms, scatter plots of the residuals, and skewness and kurtosis statistics were used to assess normality and linearity; the assumptions of multivariate analyses were found to be met. 
Principal axis factor analysis. The Biopsychosocial Endorsement Questionnaire (BEQ) was subjected to principal axis factor analysis (PAF). The Kaiser-Guttman rule (eigenvalue greater than1.0) was used to identify five components (see Table 4). Exploratory factor analysis on items 19-38 of the BEQ using principal axis factoring extraction and varimax rotation revealed a total of five components having $\geq 1.0$ eigenvalues $($ Total variance $=70.36 \%, K M O=.772)$. The eigenvalues of three of those components were higher $(7.45,2.23$ and 1.99) than the other two (1.26 \& 1.14). Cattell's scree test was used to eliminate superfluous factors (see Figure 1) and the result of a scree plot also revealed that the most efficient number of factors to be extracted was three. Items having factor loadings $\geq .40$ were regarded as having a good fit to the latent factors (Nunnally \& Bernstein, 1994) (Table 5). The three-factor solution (which accounted for $58.35 \%$ of the total variance) was observed to be parsimonious, had reasonably straightforward structure, and could be most meaningfully interpreted. Most items loaded on one of the three factors at the level of 0.60 or above (for complete factor loadings see Table 5).

Table 4

Total Variance explained

\begin{tabular}{lrrrr}
\hline Factor & & Initial Eigenvalues & \multicolumn{1}{c}{$\begin{array}{c}\text { Rotation } \\
\text { Sums of } \\
\text { Squared } \\
\text { Loadings }\end{array}$} \\
& & & & Total \\
1 & Total & \% of Variance & Cumulative \% & 4.792 \\
2 & 7.449 & 37.246 & 37.246 & 4.349 \\
3 & 2.226 & 11.131 & 48.377 & 2.528 \\
4 & 1.994 & 9.969 & 58.346 & \\
5 & 1.262 & 6.309 & 64.655 & \\
6 & 1.141 & 5.705 & 70.360 & \\
7 & .862 & 4.309 & 74.669 & \\
\hline
\end{tabular}




\begin{tabular}{llll}
\hline 8 & .663 & 3.313 & 82.177 \\
9 & .524 & 2.621 & 84.798 \\
10 & .490 & 2.449 & 87.247 \\
11 & .430 & 2.150 & 89.397 \\
12 & .411 & 2.054 & 91.451 \\
13 & .389 & 1.943 & 93.393 \\
14 & .343 & 1.714 & 95.107 \\
15 & .238 & 1.188 & 96.295 \\
16 & .216 & 1.082 & 97.378 \\
17 & .179 & .896 & 98.273 \\
18 & .137 & .686 & 98.960 \\
19 & .118 & .589 & 99.549 \\
20 & .090 & .451 & 100.00 \\
\hline
\end{tabular}

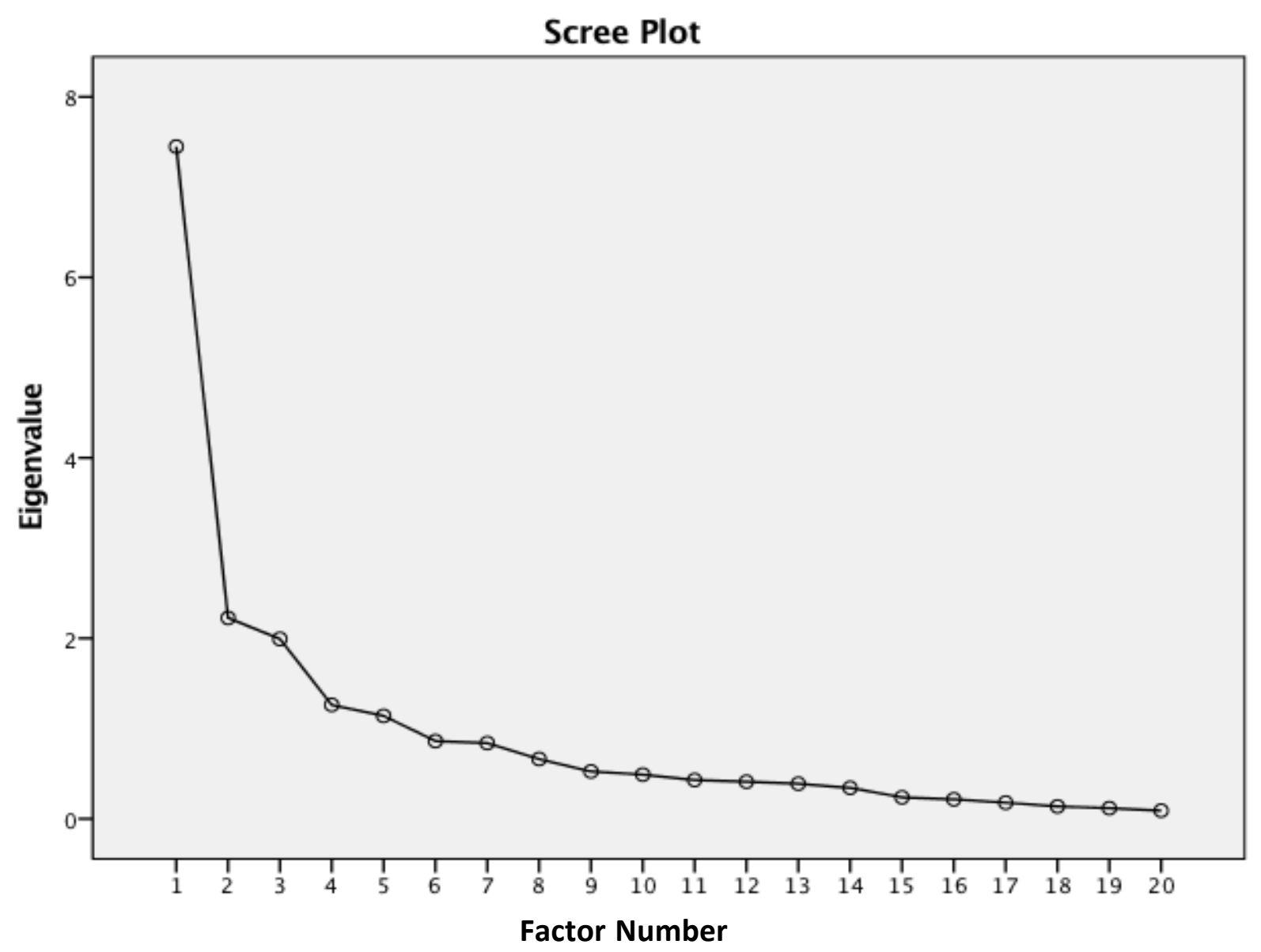

Figure 1: Scree Plot 
Table 5

Principal Axis Factor Analysis on BEQ items 19-38.

Item \# Items in Original BEQ

Factor 1 Factor 2 Factor 3

19 Treatment compliance by patients with chronic illness is facilitated by physicians who use their role as "experts" to provide comfort...

20 The emotional tone of the physician-patient relationship is a significant factor in treating...

.526

21 The quality of the physician-patient relationship forms the basis for healing

601

.134

22 The physician's support of patient autonomy increases the likelihood the patient will maintain...

.234

$.761 \quad .128$

.471

.526

.203

.108

.685

.040

23 Physicians can effectively make use of intuition in the treatment of patients with chronic illness.

.066

$.694 \quad .203$

24 Sometimes it can be beneficial for a physician to express his or her own emotions to a patient.

.046

$.713 \quad .303$

25 A physician's self-awareness is a fundamental skill in expert clinical work.

.376

$\mathbf{7 0 7} \quad .012$

26 The physician should respect the patient's wishes about the role he or she would like in the...

.456

$.414 \quad .005$

27 Cultural differences related to the patient's role in the family are likely to influence how the...

.533

.567

.064

28 Chronic illness cannot be understood apart from its cultural context.

.089

$.283 \quad .711$

29 Effective management of healthcare for patients with chronic illnesses requires psychological interventions.

30 The successful treatment of patients with chronic illnesses requires the physicians to make a long...

.027 .758

.027

.737

31 If there is a discrepancy between the patient's personal interpretation of their illness and the...

.084

.440

.600

32 Patient's perspectives on their chronic illnesses are a critical component of self-management in...

.752

.230

33 The patient's ideas and expectations about his or her illness form the basis for developing a...

.606

$.403 \quad .382$

$34 \quad$ Physicians have the responsibility to help patients articulate their perspective of their illnesses.

35 Facilitation of mental health treatment for patients with chronic illnesses can be impacted by the... 
36 The quality of the physician-patient relationship is a determining factor in the facilitation of...

37 Addressing mental health issues related to chronic illness requires an efficient approach to coordination...

38 Primary care physicians play a crucial role in the provision of mental health for patients with...

Extraction Method: Principal Axis Factoring

Rotation Method: Varimax with Kaiser Normalization

Examining the rotated factor matrix, items loading on factor 1 all reflected principles of the biopsychosocial theory related to some aspect of collaboration (i.e., physician collaboration with the patient or other healthcare providers). Items loading on factor 2, were all related to some aspect of the influence of the physician and/or the role of the physician-patient relationship in treatment.

Examination of the item clusters suggested that the first factor accounted for $37.25 \%$ of the variance and included following BEQ items: See Table 6.

Table 6

BEQ Items Subscale 1: Collaborative Care Patient's perspectives on their chronic illnesses are a critical component of self-management in healthcare.

Facilitation of mental health treatment for patients with chronic illnesses can be impacted by the physicians understanding of psychological interventions.

The quality of the physician-patient relationship is a determining factor in the facilitation of collaborative care.

Addressing mental health issues related to chronic illness requires an efficient approach to coordination of care.

Primary care physicians play a crucial role in the provision of mental health for patients with chronic illness.

Physicians have the responsibility to help patients articulate their perspective of their illnesses.

The physician should respect the patient's wishes about the role he or she would like in the decision making about their own treatment.

The patient's ideas and expectations about his or her illness form the basis for developing a mutually agreeable treatment plan with their physician. 
The second factor accounted for $11.13 \%$ of the variance and included the following BEQ items: See Table 7.

Table 7

BEQ Items Subscale 2: Physician-Patient Relationship

Treatment compliance by patients with chronic illnesses is facilitated by physicians who use their role as "experts" to provide comfort and confidence to their patients.

The emotional tone of the physician-patient relationship is a significant factor in treating patients with chronic illnesses successfully.

The quality of the physician-patient relationship forms the basis for healing.

A physician's self-awareness is a fundamental skill in expert clinical work.

Cultural differences related to the patient's role in the family are likely to influence how the patient understands and experiences a chronic illness.

The physician's support of patient autonomy increases the likelihood the patient will maintain long term change.

Physicians can effectively make use of intuition in the treatment of patients with chronic illnesses.

Sometimes it can be beneficial for a physician to express his or her own emotions to a patient.

Cronbach's alpha. In order to determine if the two identified factors are appropriate for use as the subscales collaborative care and physician-patient relationship, internal consistency was examined. Cronbach's alpha for the eight-item, first-factor, collaborative care was moderate at .87. Cronbach's alpha for the eight-item, second-factor, physician-patient relationship subscale was moderate at .87. Combined reliability for the complete BEQ item set was .90 .

\section{Correlational Analyses}

Correlations for the predictor variables and the criterion variable are provided in Table 9. The relationship between physician referrals and BEQ subscale collaborative care was significant $(r=.292, p<.05)$. The relationship between physician referrals and BEQ physicianpatient relationship subscale was significant $(r=.414, p<.01)$. However as described above, the 
third factor that emerged from the PAF was not significantly correlated with physician referrals and therefore was not entered into the regression study.

Table 6

Correlations for Variables Used in Hierarchical Regression Analyses

\begin{tabular}{lccc}
\hline Variable & 1 & 2 & 3 \\
\hline $\begin{array}{l}\text { 1.physician referrals } \\
\begin{array}{l}\text { 2.collaborative } \\
\text { care }\end{array}\end{array}$ & $.292 *$ & 1 & -- \\
$\begin{array}{l}\text { 3. physician-patient } \\
\text { relationship }\end{array}$ & $.414 * *$ & $.622 *$ & 1 \\
\end{tabular}

**. Correlation is significant at the 0.01 level (2-tailed).

*. Correlation is significant at the 0.05 level (2-tailed). 


\section{Hierarchical Regression Analysis}

Hierarchical regression analysis (HRA) was conducted to answer the primary research question with physician referrals as the criterion variable and two subscales of the BEQ entered as predictors in sequential steps: (a) collaborative care; (b) physician-patient relationship. The criterion variable of physician referrals was derived from the average of physician responses to item 12 on the BEQ $(M=3.72, S D=7.52)$.

HRA was used to examine the contributions of the two subscales of the BEQ as predictors of physician referrals to psychologists. The results of the analysis, including values of change in $R^{2}\left(\Delta R^{2}\right)$, along with unstandardized regression coefficients (B), standard errors (SE $B$ ), and standardized coefficients $(\beta)$ for the predictor variables are presented in Table 10 . In the first step of the regression analysis, the collaborative care subscale was entered. This variable accounted for a significant, but small amount of variance in physician initiated collaboration, $R^{2}=.085, F(1,67)=6.073, p<.05$. The physician-patient relationship subscale was entered in the second step of the regression analysis. This variable accounted for a significant amount of additional variance in physician referrals to psychologists beyond that explained by the collaborative care variable entered in the first step, $R^{2}=.178, \Delta R^{2}=.093, F(2$, $66)=7.237, p<.05$. The final regression model consisting of the variables collaborative care and physician-patient relationship accounted for $18 \%$ of the variance in physician referrals to psychologists. According to Cohen's standards for the behavioral sciences, this is considered a small effect size (Cohen, 1988; 1992). The physician-patient relationship was the strongest independent predictor of referrals. The next chapter will include a discussion of the findings. Table 10

Hierarchical Multiple Regression Analysis for Prediction of Physician Initiated Collaborative Behavior $(N=68)$ 


\begin{tabular}{cccccc} 
& $R^{2}$ & $\Delta R^{2}$ & B & SE B & $\beta$ \\
\hline Step 1 & & & & & \\
$\quad$ Constant & .085 & .085 & -16.77 & 8.308 & \\
Collaborative Care & & & 6.29 & 2.552 & .292 \\
Step 2 & .178 & .093 & -23.64 & 8.338 & \\
$\quad$ Constant & & & & & \\
Collaborative Care & & & 1.026 & 3.126 & .048 \\
$\quad$ Physician-Patient & & & 7.452 & 2.770 & .391 \\
$\quad$ Relationship & & & & & \\
\hline
\end{tabular}




\section{Chapter 5: Discussion}

This chapter includes a summary of the study findings and possible explanations for the findings. Limitations of the study that impact the interpretation and generalizability of the research results are explained. Finally, implications and suggestions for psychology and primary care as well as future research are discussed.

\section{Research Findings}

The overall intention of the research was to contribute to the broader chronic illness narrative by piloting and refining a survey tool that could reveal critical components of the biopsychosocial theory and their relationship to chronic care, specifically provider collaboration.

The results of the initial exploratory analysis of the Biopsychosocial Endorsement Questionnaire (BEQ) are generally optimistic regarding the potential for the development of an instrument that can effectively measure primary care providers' endorsements of a biopsychosocial approach applied to the treatment of patients with chronic illnesses. The final three-factor solution accounted for $58 \%$ of the variance. According to the literature, within the social sciences, it is common to consider a solution that accounts for $60 \%$ of the variance as satisfactory (Hair et al., 2014; Nunnally \& Bernstein, 1994; Tinsley \& Tinsley, 1987). Interpretation is based on finding which variables are most strongly correlated with each factor. A .30 loading translates to approximately $10 \%$ of variance being explained, and a .50 loading denotes that $25 \%$ of the variance is accounted for by the variable (Hair et al., 2014). As a rule of thumb, when determining the number of variables, the proportion of variance accounted for should be at least .50 (Merenda, 1997). In the BEQ the first factor is strongly correlated with seven of the original variables from the hypothesized subscales collaborative care and illness narrative. This factor can be viewed as a measure of collaborative care and the role of the 
patient's illness narrative. However, the first factor correlates most strongly with collaborative care variables. The second factor is strongly correlated with eight of the original variables from the hypothesized subscales physician-patient relationship and physician self-awareness. This factor can be viewed as a measure of the importance of the physician-patient relationship and the physician's self-awareness as it relates to treating patients from a biopsychosocial perspective. However, the second factor correlates most strongly with physician-patient relationship variables. The third factor is strongly correlated with four of the original variables from the hypothesized inclusion of psychosocial factors subscale. This component can be viewed as a measure of the importance of the inclusion of psychosocial factors for the treatment of patients with chronic illnesses. This three-factor solution is a departure from the hypothesized five-factor solution.

Overall, the BEQ would benefit from the collection of another trial set of data with a greater number of responses. The items intended to represent the hypothesized subscales physician self-awareness and illness narrative did not show salient associations with the underlying factor, and the subscale inclusion of the psychosocial factors was not significantly correlated at the bivariate level. However, the results of the principal axis factor analysis (PAF) could have been effected by the sample size. Additionally, before dropping any items from the measure it would be beneficial to modify the items that did not perform well in the PAF. Subsequently, in order to increase the variance explained by the model, I could write additional items related to the three emerging subscales (physician-patient relationship, collaborative care, and inclusion of psychosocial factors) and collect yet another trial set of data. These items would include any other variables that should be related as well as not related to the underlying factor. Since the subscales that emerged from the PAF were used in the subsequent analysis to 
determine the predictive value of the BEQ as it relates to physician referrals to psychologists, those results should be interpreted judiciously.

The secondary aim of the study was to test the effectiveness of the subscales of the BEQ for predicting physician referrals to psychologists. The results of the PAF suggested a threefactor solution, however the subscale, inclusion of psychosocial factors, was not significantly correlated at the bivariate level and therefore was not included in the analysis.

A hierarchical regression analysis (HRA) was used to investigate how the BEQ subscales physician-patient relationship and collaborative care might be predictive of physician referrals to psychologists. The predictor variables represented the two strongest factors following the PAF. Specifically, it was hypothesized that the two sets of variables labeled, collaborative care and physician-patient relationship, would each contribute significantly to predicting collaborative behavior with psychologists. Overall, the final regression model accounted for only $18 \%$ of the variance in collaborative behavior scores, which is considered a small effect size according to Cohen's (1988) standards. Further research is needed to explain the complex relationships of factors impacting physician initiated collaborative behavior with psychologists. Additionally, although an a priori analysis deemed the sample size appropriate for the primary regression analyses, the study may have been underpowered and unable to detect specific independent contributions of variables.

\section{Limitations}

The reasons for research not supporting a proposed hypothesis often rest in the design limitations. There are constraints on any research design and process; these can be of value in the discussion of the overall objectives and recommendations for future research. In this project, 
these included characteristics of the methods and data, to include response rates and variability within those responses.

Generalizability of the sample. The generalizability of the findings are limited by the population of the participants and the demographics and health statistics of the patients they treat. Participants were a convenience sample of primary care physicians practicing in a state comprised of a largely rural demographic treating patients with increased incidents of chronic illness, which has implications for the availability of primary care physicians and psychologists to undertake integrative care initiatives.

The current patient to primary care physician ratio of $1,392: 1$ is lower than the national average of 1,463:1. Although on the surface these ratios would not appear to be evidence of a shortage, when considered along with the health statistics of the population and healthcare utilization it puts West Virginia up against a provider crisis as soon as 2030 (Peterson et al., 2013). Similarly, West Virginia has a shortage of licensed psychologists practicing in the state. The United States Department of Health and Human Services, Health Resources and Service Administration has identified 129 areas in the state where there are shortages of mental health providers, including 30 entire counties which comprise a little over half of the counties in the state (West Virginia Psychological Association, 2013).

According to the U.S. Census Bureau (2015) the population of West Virginia is predominately white $(93.6 \%) ; 38 \%$ of the population lives in rural areas versus rural areas that reflect a more urban nature; and the poverty rate ranges from $19 \%$ in rural areas to $17 \%$ in areas that are considered urban despite a rural classification (areas where the population is between 2,500 and 49,999). Poverty and chronic illness are connected; poorer people are at highest risk for developing chronic health conditions and, in turn, these conditions can limit a family's 
chances to improve their economic status as well as decrease their ability to access healthcare (World Health Organization, n.d).

According to the West Virginia Health Statistics Center (2017), West Virginia is ranked the highest in the nation for the prevalence of cardiovascular disease (14.1\%) and chronic obstructive pulmonary disease (13.5\%). More than one in 10 adults had diabetes $(14.1 \%)$, ranking the state $4^{\text {th }}$ nationally. The prevalence of depression among adult West Virginians is $23.6 \%$, also higher than the national average $(17.8 \%)$.

The population of West Virginia was relevant to an investigation such as this because the high incidence rates and challenges associated with facilitating positive health outcomes in poor, rural areas could find value in an integrative care model. Yet, those physicians may lack access to education about the model and opportunities to participate in research-based projects. Research efforts have predominately focused on programs or projects in urban hospitals that receive or are affiliated with government funding for their research. Furthermore, the availability of psychologists for collaboration in the most rural parts of the state may have been close to nonexistent. It is worth noting that many of the participants in this study were not aware of a psychologist practicing in their community $(n=34,48.6 \%)$ and did not have a psychologist on staff in their clinic $(n=62,87.3 \%)$. This is consistent with a study that reported that despite a growing number of primary care clinics having ready access to mental health providers, most still do not work in integrated settings, and even fewer of these exist in rural communities (Karlin \& Karel, 2013).

In addition, the population these physicians serve does not constitute a diverse population, economically, racially or ethnically. There was no opportunity to learn more about 
the culturally specific social issues that influence healthcare delivery, except as it relates to the culture of a specific region of the country, Appalachia.

Access to participants. The challenges inherent in accessing participants for research studies in rural areas in addition to those associated with surveying physicians in busy practices influenced the outcome of the research project. Potential participants working in rural areas are not clustered in high density locations, increasing the time and resources needed to survey them in person. Limitations in budget and time inherent in dissertation research made this impossible so the decision was made to survey via email.

Despite the endorsement and direct support in the data collection process of the West Virginia Medical Association, the response rate of 5.77\% was disappointing. The association reported that I could expect a response rate of $70 \%$ (D. Scalise, personal communication, April $24,2017)$ and the survey literature indicated that $30 \%$ was common. The reasons why participants were less likely to respond are not clear and would require follow up inquiries, outside the scope of this project. Conjectures can be made and the recommendation would be that gathering data on concepts that are relatively new and multifaceted would best be done in an educational context, using the process of continuing medical education with a pre-and post-test collection.

Participation and response bias. Participants self-selected to participate in this study and that may have limited the generalizability of the findings (Patton, 2000). It is possible that only primary care physicians who felt strongly positive or strongly negative about the topic responded and that would lead to systemic bias. In general, there is a tendency for some people to respond to online surveys and others to never do so (Wright, 2005). 
The present study may have been vulnerable to the following: selective memory, telescoping, exaggeration, and social desirability (Patton, 2000). Selective memory occurs when a participant misremembers or forgets an experience or events that are related to the questionnaire items. Telescoping is present when a participant misremembers the time frame in which an event occurred. In the case of the present study, participants may not have remembered making a referral to a psychologist, been able to recall a time when they collaborated with a psychologist, or they could have misremembered the time frame in which collaboration occurred. Exaggeration occurs when participants over-represent their answers either positively or negatively. Some of the cases in this study contained outliers, these may be attributed to exaggeration on the part of the participant. Social-desirability occurs when participants try to anticipate what the researcher is seeking and answer accordingly (Brutus, Aguinis, \& Wassmer, 2013). In the case of the present study, if a physician desired to work from a biopsychosocial perspective they may have answered the questions on the attitude section of the questionnaire in a socially desirable way, yet answered the preceding questions related to collaboration and referrals differently

Measures. At the time of this undertaking, no survey instruments designed to collect relevant data could be found in the literature. This can be a problem in exploratory research projects. It was an opportunity to add the design of a new survey tool for use by both researchers and possibly psychologists in their outreach to physicians. Therefore, a questionnaire, the BEQ, was created to survey the target group using the developmental steps and sequence outlined by DeVellis (2003) and Croker and Algina (1986). The items used to measure biopsychosocial endorsement were found to be highly correlated and reliable as well as internally consistent, which was a strength of the measure. 
Instrument validation and tests of reliability require extensive testing, modifications and retesting. The time and budget constraints of this dissertation made achieving the goal of a research instrument that achieves test-retest reliability standards impossible. The project was set to pilot the instrument as part of an exploratory study, one that can be taken and developed further in future research.

\section{Recommendations for Further Study}

Future research in this area should focus on refining both the instrumentation and methodology for gathering relevant, high quality data to support furthering the initiatives designed to improve collaboration between primary care physicians and psychologists. This will in turn serve to continue to enhance the broader chronic illness narrative and improve the quality of life and healthcare outcomes of patients with chronic illnesses. Given the healthcare needs of rural areas, it would behoove researchers to continue to focus on this population. Rural healthcare is a continuing discussion as policymakers, practitioners, and researchers attempt to reduce the barriers to access, to include financial restraints, transportation issues, confidence in both the quality of care and associated need for confidentiality. This includes achieving timely access to both primary care and mental health care to achieve the best outcomes possible (Rural Health Information Hub, 2017).

Instrument design. The further development of the BEQ would benefit both the physician and the psychologist as they seek to collaborate on a common theoretical ground. Revisiting the process used to date with more review of the literature, development and modification of questions with larger expert panels, and focus on different environments would be a first step. Future research also needs to focus on the validation of the BEQ to establish it is a viable instrument. 
A more comprehensive research project design is also a recommendation for future work in this area. What was novel about this study was its emphasis on the role of the biopsychosocial theory and its application to the treatment of patients with chronic illnesses and the relationship to physician initiated collaborative behavior with psychologists. However, attempts to provide an initial validation for the instrument indicated that there are other relationships or factors absent from the BEQ as it is currently written for understanding its predictive utility for physician initiated collaborative behavior. These may be aspects related to the biopsychosocial theory as well as variables unrelated to a theoretical basis for physician behaviors.

There was a piece of anecdotal evidence provided by one of this study's participants to support the recommendation for a more comprehensive survey tool. The physician emailed the director of the West Virginia Medical Association expressing appreciation for the intent of the research but felt it would not effectively sort out significant information related to other barriers to collaboration such as availability of appropriate practitioners, time to make a referral, and effective collaborative communication (D. Scalise, personal communication, May 5, 2017).

Additional questions from previously validated instruments related to barriers to successful collaboration, including those that seek to have physicians to report on the accessibility of psychologists, mechanics of and time associated with collaborating, and the existence and effect of the stigma experienced by people who are diagnosed with mental health disorders and seek treatment would be valuable in efforts to develop a comprehensive survey tool (Chomienne et al., 2010; Gatchel \& Oordt, 2003; Grenier at al., 2008; Lee et al., 2012).

This is consistent with the research done by Beacham et al. (2012) that identified the causal factors associated with physicians' negative attitudes toward collaboration with psychologists, namely lack of an understanding of psychological frameworks, a history of 
difficulty making referral(s) to a psychologist, and longstanding tendency among patients and providers to stigmatize mental health disorders. Because understanding and predicting physician initiated collaboration is a multidimensional construct, it would make sense that the most effective instrument for predicting this type of behavior would be multifaceted as well.

Expanding the primary care participant population. The focus of healthcare reform and the revitalization of primary care has focused on the role of primary care physicians. However, these efforts have also revealed a shortage of primary care physicians nationwide. As a result, physician's assistants and nurse practitioners are also now considered first line providers and in many clinical settings have the same clinical roles and responsibilities as primary care physicians (Peterson et al., 2013). Future studies should include primary care physician assistants and nurse practitioners in order to increase the overall sample size and variability in participant responses.

Investigating the behavior health component. This exploratory approach to the subject of collaboration steps toward integrative healthcare intentionally did not include the behavioral health side of the equation. For the most effective of partnerships, the practicing psychologist needs to be the subject of a parallel line of research. If the goals of collaborative care interventions include improved screening and diagnosis, increased patient satisfaction, improved self-management skills, and better overall health outcomes (Thota et al., 2012), then these elements are present in the knowledge and skill set of the psychologists. In efforts to locate qualified professionals in rural areas of healthcare, it would be of benefit to determine what those skillsets must be and how to increase the knowledge levels of already practicing psychologists through continuing education efforts as well as preparing new psychologists in their doctoral training. 


\section{Conclusion}

Leaders in psychology have been urging those in the profession to embrace the opportunity to establish themselves as an integral healthcare provider and assertively create a role for themselves in integrated healthcare intervention equations that can improve the outcomes for people living with chronic medical conditions. Collaboration with mental health care professionals and mental health care have become increasingly important in models of healthcare intervention for the treatment of patients living with chronic illnesses, especially those experiencing comorbidities. Research has revealed that when physicians collaborate with mental healthcare providers patients are more likely to have improved health outcomes, enjoy a greater sense of satisfaction with their healthcare and healthcare providers, and in some instances become more effective at self-managing their chronic illnesses. However, collaboration is still not a regular practice for most physicians.

This study is novel in that it was the first to apply the principles of biopsychosocial theory for the treatment of patients with chronic illness to a sample of primary care physicians. It was successful at providing a preliminary answer to the question of whether or not physicians might endorse the biopsychosocial conceptual framework. It also provides support for further refinement of the piloted Biopsychosocial Endorsement Questionnaire (BEQ) and the inclusion of biopsychosocial principles in future research that seeks to explain the complex relationships of factors impacting physician initiated collaborative behavior, especially elements of the physician-patient relationship. This study should serve to broaden the conversations in psychology and primary care related to the disconnections that currently exist between endorsement of the biopsychosocial approach to healthcare and actions that are normally part of the process of implementing patient-centered integrated care. 


\section{References}

American Psychological Association. (2010). Health-care reform. Washington, DC: Author. Retrieved from http://www.apa.org/healthreform/

American Psychological Association. (2015). Competencies for psychology practice in primary care. Retrieved from http://www.apa.org/ed/resources/competencies-practice.pdf. American Psychological Association. (2017). Helping people improve their lives. Psychology: Science in Action. Retrieved from http://www.apa.org/action/careers/improve-lives/

Amiel, J. M., \& Pincus, H. A. (2011). The medical home model: new opportunities for psychiatric services in the United States. Current Opinion in Psychiatry, 24(6), 562-568.

Arena, R., Williams, M., Forman, D. E., Cahalin, L. P., Coke, L., Myers, J., ...\& Lavie, C. J. (2012). Increasing referral and participation rates to outpatient cardiac rehabilitation: The 
valuable role of healthcare professionals in the inpatient and home health settings - A science advisory from the American Heart Association. Circulation, 125(10), 1321-1329. Asner, B., Atkins, L., Wilkniss, S. \& Dentzer, S. (2017). Coordinated care and beyond: The future of integrated care for complex chronic conditions: What's working, what's not. [Undedited transcript]. Retrieved from http://www.allhealthpolicy.org/coordinated-careand-beyond-the-future-of-integrated-care-for-complex-chronic-conditions-whatsworking-whats-not/

Babbie, E. (2012). The practice of social research. Cengage Learning.

Barlow, David H. (2004). Psychological treatments. American Psychologist, 59(9), 869-878.

Baron, R. J. (2010). What's keeping us so busy in primary care? A snapshot from one practice. New England Journal of Medicine, 362(17), 1632-1636.

Bauer, U.E., Briss, P.A., Goodman, R.A., \& Bowman, B.A. (2014). Prevention of chronic disease in the $21^{\text {st }}$ century: Elimination of the leading preventable causes of premature death and disability in the USA. The Lancet, 384(9937), 45-52.

Beacham, A., Herbst, A., Streitwieser, T., Scheu, E., \& Sieber, W. (2012). Primary care medical provider attitudes regarding mental health and behavioral medicine in integrated and nonintegrated primary care practice settings. Journal of Clinical Psychology in Medical Settings, 19(4), 364-375.

Berenson, R. A., Devers, K. J., \& Burton, R. A. (2011). Will the patient-centered medical home transform the delivery of health care? Retrieved from http://www.rwjf.org/qualityequality/product.jsp?id=72660.

Bibace, R., Walsh, M.E. (1979). Clinical developmental psychologists in family practice settings. Professional Psychology, 10(4), 441-450. 
Bowen, J. L., Stevens, D. P., Sixta, C. S., Provost, L., Johnson, J. K., Woods, D. M., \& Wagner, E. H. (2010). Developing measures of educational change for academic health care teams implementing the chronic care model in teaching practices. Journal of General Internal Medicine, 25(S4), 586-592.

Bray, J. H. (2004). Training primary care psychologists. Journal of Clinical Psychology in Medical Settings, 11(2), 101-107.

Bray, J. (2011). Training for the future of psychology practice. Training and Education in Professional Psychology, 5(2), 69-72.

Bryman, A. (2012). Social research methods. (4 ${ }^{\text {th }}$ ed.). Oxford University Press.

Callander, E. J., Schofield, D. J., \& Shrestha, R. N. (2013). Chronic health conditions and poverty: a cross-sectional study using a multidimensional poverty measure. BMJ Open, 3(11), e003397. http://doi.org/10.1136/bmjopen-2013-003397

Canady, V. (2016, July). CMS proposal to change payment rates promotes coordinated care. Mental Health Weekly, 26.

Cohen, J. (1988). Statistical power analysis for the behavioral sciences (2nd ed). Hillsdale, NJ: Erlbaum.

Collins, C., Hewson, D. L., Munger, R., \& Wade, T. (2010). Evolving models of behavioral health integration in primary care. New York, NY: Milbank Memorial Fund.

Coventry, P., Lovell, K., Dickens, C., Bower, P., Chew-Graham, C., McElvenny, D., ... Gask, L. (2015). Integrated primary care for patients with mental and physical multimorbidity: cluster randomised controlled trial of collaborative care for patients with depression comorbid with diabetes or cardiovascular disease. The BMJ, 350, 1-12 http://doi.org/10.1136/bmj.h638 
Coventry, P. A. (2013). Better together? A naturalistic qualitative study of inter-professional working in collaborative care for co-morbid depression and physical health problems. Implementation Science, 8, 110.

Cozby, P.C. (2009). Methods in behavioral research (10 $10^{\text {th }}$ ed.). New York, NY: McGraw Hill. Creswell, J. W. (2012). Qualitative inquiry and research design: Choosing among five approaches. Thousand Oaks, CA: Sage Publications.

Croghan, T. W., \& Brown, J. D. (2010). Integrating mental health treatment into the patient centered medical home. AHRQ Publication No. 10-0084. Retrieved from https://www.pcmh.ahrq.gov/sites/default/files/attachments/Integrating\%20Mental\%20He alth\%20and\%20Substance\%20Use\%20Treatment\%20in\%20the\%20PCMH.pdf

Cunningham, P. D., Connor, P. D., Manning, J. S., Stegbauer, C. C., \& Mynatt, S. L. (2009). Evaluation of mood disorder patients in a primary care practice: Measures of affective temperament, mental health risk factors, and functional health in a retrospective, descriptive study of 35 patients. Primary Care Companion to The Journal of Clinical Psychiatry, 11(2), 68-73.

Cunningham PJ. (2009). Beyond parity: Primary care physicians' perspectives on access to mental healthcare. Health Aff (Millwood). 2009; 28:w490-501. [PubMed: 19366722]

Curry, L. A., Nembhard, I. M., \& Bradley, E. H. (2009). Qualitative and mixed methods provide unique contributions to outcomes research. Circulation, 119(10), 1442-1452.

de Groot, M., \& Fisher, L. (2011). Building a pipeline of training for behavioral diabetes researchers and clinicians: A call for a national dialogue. Current Diabetes Reports, 11, 503-510. doi:10.1007/s11892-011-0231-X 
Denelsky, G.Y. (1996). Collaborative practice: Psychologists and internists. In R.J. Resnick \& R.H. Rozensky (Eds.), Health Psychology Through the Life Span: Practice and Research, 101-107.

Denzin, N. K., \& Lincoln, Y. S. (2011). The SAGE handbook of qualitative research. Thousand Oaks, CA: Sage Publications.

Dickinson, W. P., Dickinson, L. M., Nutting, P. A., Emsermann, C. B., Tutt, B., Crabtree, B. F., ... \& West, D. R. (2014). Practice facilitation to improve diabetes care in primary care: a report from the EPIC randomized clinical trial. Annals of Family Medicine, 12(1), 8-16. http://doi.org/10.1370/afm.1591

Dobele, A. \& Lindgreen, A. (2011), Exploring the nature of value in the word-of-mouth referral equation for health care, Journal of Marketing Management, 27(3/4), 269-290. doi: 10.1080/0267257X.2011.545677

Dym, B. \& Berman, S. (1986). The primary health care team: Family physician and family therapist in joint practice. Family Systems Medicine, Vol 4(1), 1986, 9-

21. http://dx.doi.org/10.1037/h0089687

Ell, K., Katon, W., Cabassa, L. J., Xie, B., Lee, P. J., Kapetanovic, S., \& Guterman, J. (2009). Depression and diabetes among low-income Hispanics: Design elements of a socioculturally adapted collaborative care model randomized controlled trial. International Journal of Psychiatry in Medicine, 39, 113-132.

Engel, G. L. (1977). The need for a new medical model: The challenge for biomedicine. Science, 196, 129-136.

Epstein, R. M., Fiscella, K., Lesser, C. S., \& Stange, K. C. (2010). Why the nation needs a policy push on patient-centered health care. Health Affairs, 29(8), 1489-1495. 
Faul, F., Erdfelder, E., Lang, A. G., \& Buchner, A. (2007). G*Power 3: A flexible statistical power analysis for the social, behavioral, and biomedical sciences. Behavior Research Methods, 39, 175-191.

Fickel, J. J., Parker, L. E., Yano, E. M., \& Kirchner, J. E. (2007). Primary care--mental health collaboration: An example of assessing usual practice and potential barriers. Journal of Interprofessional Care, 21(2), 207-216.

Fise, P., Marsh, C., Nelson, S., Romley, J., \& Dash, S. (2017). Coordinated care and beyond: Future trends in chronic care. [Undedited transcript]. Retrieved from http://www.allhealthpolicy.org/coordinated-care-and-beyond-future-trends-in-chroniccare/

Fisher, L., Dickinson, W.P. (2014). Psychology and primary care: New collaborations for providing effective care for adults with chronic health conditions. American Psychologist,69(4), 355-3632.

Fleury, M. J., Imboua, A., Aubé, D., \& Farand, L. (2012). Collaboration between general practitioners (GPs) and mental healthcare professionals within the context of reforms in Quebec. Mental Health in Family Medicine, 9(2), 77-90.

Francis, J. J., Johnston, M., Robertson, C., Glidewell, L., Entwistle, V., Eccles, M. P., \& Grimshaw, J. M. (2010). What is an adequate sample size? Operationalizing data saturation for theory-based interview studies. Psychology and Health, 25(10), 1229-1245.

Frankel, R.M. Quill, T.E., \& McDaniel, S.H. (2003). The biopsychosocial approach: Past, present, future. Rochester, NY: University Rochester Press. 
Franz, C. E., Barker, J. C., Kim, K., Flores, Y., Jenkins, C., Kravitz, R. L., \& Hinton, L. (2010). When help becomes a hindrance: Mental health referral systems as barriers to care for primary care physicians treating patients with Alzheimer's disease. The American Journal of Geriatric Psychiatry, 18(7), 576-585.

Gesme, D., \& Wiseman, M. (2010). How to implement change in practice. Journal of Oncology Practice, 6(5), 257-259.

Goldberg D. (2010). The detection and treatment of depression in the physically ill. World Psychiatry, 9, 16-20.

Graves, K.D. \& Miller, P.M. (2016). Behavioral medicine in the prevention and treatment of cardiovascular disease. Behavior Modification, 27(1), 3-25.

Gravely-Witte, S., Leung, Y. W., Nariani, R., Tamim, H., Oh, P., Chan, V. M., \& Grace, S. L. (2010). Effects of cardiac rehabilitation referral strategies on referral and enrollment rates. Nature Review Cardiology, 7(2), 87-96.

Heron, M. (2011, August 26). Deaths: Leading causes for 2007. National Vital Statistics Reports, 59(8). Retrieved from http://www.cdc.gov/nchs/data/nvsr/nvsr59/nvsr59_08.pdf

Herring, M. P., Puetz, T. W., O’Connor, P. J., \& Dishman, R. K. (2012). Effect of exercise training on depressive symptoms among patients with a chronic illness: A systematic review and meta-analysis of randomized controlled trials. Archives of Internal Medicine, 172(2), 101-111.

Holleman, W. L., Bray, J. H., Davis, L., \& Holleman, M. C. (2004). Innovative ways to address the mental health and medical needs of marginalized patients: Collaborations between family physicians, family therapists, and family psychologists. The American Journal of Orthopsychiatry, 74(3), 242-252. 
Hunter, Christopher L., \& Goodie, Jeffrey L. (2010). Operational and clinical components for integrated-collaborative behavioral healthcare in the patient-centered medical home. Families, Systems, \& Health, 28(4), 308-321.

Institute of Medicine. (2004). Improving medical education: Enhancing the behavioral and social science content of medical school curricula. Washington, DC: The National Academic Press.

Institute of Medicine. (2012a). Living well with chronic illness: A call for public health action. Washington DC: National Academies Press. Retrieved from: http://www.iom.edu/Reports/2012/Living-Well-with-Chronic-Illness.aspx Institute of Medicine. (2012b). Primary care and public health: Exploring integration to improve population health. Washington DC: National Academies Press. Retrieved from http://www.iom.edu/Reports/2012/Primary-Care-and-Public-Health.aspx

Interprofessional Education Collaborative Expert Panel. (2011). Core competencies for interprofessional collaborative practice: Report of an expert panel. Washington, DC: Interpersonal Education Collaborative. Retrieved from: http://www.aacn.nche.edu/education-resources/ipecreport.pdf

Jacob, V., Chattopadhyay, S. K., Sipe, T. A., Thota, A. B., Byard, G. J., \& Chapman, D. P. (2012). Economics of collaborative care for management of depressive disorders: A community guide systematic review. American Journal of Preventive Medicine, 42(5), $539-549$.

Jaini, P. A., \& Lee, J. S.-H. (2015). A review of 21 st century utility of a biopsychosocial model in United States medical school education. Journal of Lifestyle Medicine, 5(2), 49-59. 
Johnson, J. A., Al Sayah, F., Wozniak, L., Rees, S., Soprovich, A., Chik, C. L., ... Majumdar, S. R. (2012). Controlled trial of a collaborative primary care team model for patients with diabetes and depression: Rationale and design for a comprehensive evaluation. BMC Health Services Research, 12, 258.

Johnson, S. B. (2013). Increasing psychology's role in health research and health care. American Psychologist, 68, 311-321.

Kainz, K. (2002). Barriers and enhancements to physician-psychologist collaboration. Professional Psychology: Research and Practice, 33(2), 169-175.

Kane, R. L., Priester, R., \& Totten, A. (2005). Meeting the challenge of chronic illness. Baltimore, MD: Johns Hopkins University.

Katon W, Von Korff M, Lin E, Walker E, Simon GE, Bush T, Robinson P, \& Russo J. (1995). Collaborative management to achieve treatment guidelines. Impact on depression in primary care. JAMA, 13(5),1026-1031.

Katon, W. J., Rutter, C., Simon, G., Lin, E. H., Ludman, E., Ciechanowski, P., . . \& Von Korff, M. (2005). The association of comorbid depression with mortality in patients with Type 2 diabetes. Diabetes Care, 28, 2668-2672.

Katon, W. Lin, E.H., \& Kroenke, K. (2007). The association of depression and anxiety with medical symptom burden in patients with chronic medical illness, General Hospital Psychiatry, 29(2), 147-155.

Katon, W. J., Lin, E. H., Von Korff, M., Ciechanowski, P., Ludman, E. J., Young, B., ... \& McCulloch, D. (2010). Collaborative care for patients with depression and chronic illnesses. New England Journal of Medicine, 363(27), 2611-2620. 
Katon, W. J. (2011). Epidemiology and treatment of depression in patients with chronic medical illness. Dialogues in Clinical Neuroscience, 13(1), 7-23. Retrieved from http://www.ncbi.nlm.nih.gov/pmc/articles/PMC3181964/

Katon, W. J., \& Unützer, J. (2013). Health reform and the Affordable Care Act: The importance of mental health treatment to achieving the triple aim. Journal of Psychosomatic Research, 74(6), 533-537.

Kazak, A. E., Hiroto, K., Nash, J. M., \& Kaslow, N. J. (2017). Psychologists in patient-centered medical homes (PCMHs): Roles, evidence, opportunities, and challenges. American Psychologist, 72(1), 1-12.

Knowles, S. E., Chew-Graham, C., Coupe, N., Adeyemi, I., Keyworth, C., Thampy, H., \& Coupe, N., \& Coventry, P. A. (2015). Managing depression in people with multimorbidity: A qualitative evaluation of an integrated collaborative care model. $B M C$ Family Practice, 16, 32. http://doi.org/10.1186/s12875-015-0246-5

Knowles, P. (2009). Collaborative communication between psychologists and primary care providers. Journal of Clinical Psychology in Medical Settings, 16(1), 72-76.

Kroenke, K., Spitzer, R. L., \& Williams, J. B. W. (2001). The PHQ-9: Validity of a Brief Depression Severity Measure. Journal of General Internal Medicine, 16(9), 606-613.

Landrine, H., Klonoff, E. A. \& Brown-Collins, A. (1992), Cultural diversity and methodology in feminist psychology: Critique, proposal, empirical Example. Psychology of Women Quarterly, 16, 145-163. 
Lin, E. H., Rutter, C. M., Katon, W., Heckbert, S. R., Chiechanowski, P., Malia, M., \& Von Korff, M. (2010). Depression and advanced complications of diabetes: A prospective cohort study. Diabetes Care, 33(2), 264-269.

Lin, E. H., Von Korff, M., Ciechanowski, P., Peterson, D., Ludman, E. J., Rutter, C. M., ...\& Katon, W. J. (2012). Treatment adjustment and medication adherence for complex patients with diabetes, heart disease, and depression: A randomized controlled trial. The Annals of Family Medicine, 10(1), 6-14.

Lustman, P.J., Anderson, R.J., Freedland, K.E., de Groot, M., Carney, R.M., \& Clouse, R.E. (2000). Depression and poor glycemic control. Diabetes Care, 23 (7), 934-42.

Lyles, C. R., Harris, L. T., Le, T., Flowers, J., Tufano, J., Britt, D., ...\& Ralston, J. D. (2011). Qualitative evaluation of a mobile phone and web-based collaborative care intervention for patients with type 2 diabetes. Diabetes Technology \& Therapeutics, 13(5), 563-569.

McCorkle, R., Ercolano, E., Lazenby, M., Schulman-Green, D., Schilling, L. S., Lorig, K., \& Wagner, E. H. (2011). Self-management: Enabling and empowering patients living with cancer as a chronic illness. CA: Cancer Journal for Clinicians, 61(1), 50-62.

McDaniel, S.H. \& LeRoux, P. (2006). An overview of primary care family psychology. Journal of Clinical Psychology in Medical Settings, 14 (1), 23-32.

McDaniel, S., Grus, C., Cubic, B., Hunter, C., Kearney, L., Schuman, C., . . \& Johnson, S. B. (2014). Competencies for psychology practice in primary care. American Psychologist, 69, 409-429.

McDaniel, S., \& DeGruy III, F. (2014). An introduction to primary care and psychology. Special issue: Primary care and psychology. American Psychologist, 69(4), 325-331.

McGregor, M., Lin, E. H. B., \& Katon, W. J. (2011). TEAMcare: An integrated multicondition 
collaborative care program for chronic illnesses and depression. The Journal of Ambulatory Care Management, 34(2), 152-162.

Miller, W.L., Crabtree, B.F., Nutting, P.A., Stange, K.C., \& Jaén, C.R. (2010) Primary care practice development: A relationship-centered approach. Annals of Family Medicine, 8(Supplement 1), s68-79.

Miller-Matero, L., Dykuis, K. E., Albujoq, K., Martens, K., Fuller, B. S., Robinson, V., . . \& \& Willens, D. E. (2016). Benefits of integrated behavioral health services: The physician perspective. Families, Systems \& Health: The Journal of Collaborative Family HealthCare, 34(1), 51-55.

Nash, J. M., McKay, K. M., Vogel, M. E., \& Masters, K. S. (2012). Functional roles and foundational characteristics of psychologists in integrated primary care. Journal of Clinical Psychology in Medical Settings, 19(1), 93-104.

National Center for Chronic Disease and Health Promotion, Centers for Disease Control and Prevention (2012). Chronic disease prevention and health promotion domains. Retrieved from http://www.cdc.gov/chronicdisease/about/foa/docs/Four-Domains-Nov2012.pdf

Newing, H., Eagle, C. M., Puri, R. K., \& Watson, C. W. (2011). Conducting research in conservation: social science methods and practice (p. 376). Abingdon, UK: Routledge.

Newsom, J. T., Huguet, N., McCarthy, M. J., Ramage-Morin, P., Kaplan, M. S., Bernier, J., ...\& Oderkirk, J. (2012). Health behavior change following chronic illness in middle and later life. The Journals of Gerontology Series B: Psychological Sciences and Social Sciences, 67B(3), 279-288.

Nordal, K.C. (2012). Healthcare reform: Implications for independent practice. Professional Psychology: Research and Practice, 43(6), 535-544. 
Nutting, P. A., Crabtree, B. F., Miller, W. L., Stange, K. C., Stewart, E., \& Jaén, C. (2011). Transforming physician practices to patient-centered medical homes: Lessons from the national demonstration project. Health Affairs, 30(3), 439-445.

O’Malley, A. S., Grossman, J. M., Cohen, G. R., Kemper, N. M., \& Pham, H. H. (2010). Are electronic medical records helpful for care coordination? Experiences of physician practices. Journal of General Internal Medicine, 25(3), 177-185.

Park, M., Katon, W., \& Wolf, F. (2013). Depression and risk for mortality in individuals with diabetes: A meta-anaylsis and systematic review. General Hospital Psychiatry, 35(3), 217-225.

Pearce, M. J., Koenig, H. G., Robins, C. J., Nelson, B., Shaw, S. F., Cohen, H. J., \& King, M. B. (2015). Religiously integrated cognitive behavioral therapy: A new method of treatment for major depression in patients with chronic medical illness. Psychotherapy, 52(1), 56.

Petterson, S.M., Cai, A., Moore, M., \& Bazemore, A.(2013, September). State-level projections of primary care workforce, 2010-2030. Washington, D.C.: Robert Graham Center.

Pinquart, M., \& Shen, Y. (2011a). Depressive symptoms in children and adolescents with chronic physical illness: An updated meta-analysis. Journal of Pediatric Psychology, $36(4), 375-384$

Pinquart, M., \& Shen, Y. (2011b). Behavior problems in children and adolescents with chronic physical illness: A meta-analysis. Journal of Pediatric Psychology, 36(9), 1003-1016. doi: 10.1093/jpepsy/jsr042

Piper, M. E., Baker, T. B., Mermelstein, R., Collins, L. M., Fraser, D. L., Jorenby, D. E., ...\& Fiore, M. C. (2013). Recruiting and engaging smokers in treatment in a primary care 
setting: Developing a chronic care model implemented through a modified electronic health record. Translational Behavioral Medicine, 3(3), 253-263. doi: 10.1007/s13142$012-0178-8$

Pisani, A. R., Berry, S. L., \& Goldfarb, M. (2005). A Predoctoral Field Placement in Primary Care: Keeping It Simple. Professional Psychology: Research and Practice, 36(2), 151.

Public Health Accreditation Board. (2011). Standards and Measures: Version 1.0. Retrieved from http://www.phaboard.org/wp-content/uploads/PHAB-Standards-and-MeasuresVersion-1.0.pdf

Raggi, V. L. (2011). Internship and Fellowship Experiences: Preparing Psychology Trainees for Effective Collaboration with Primary Care Physicians. In Pediatricians and Pharmacologically Trained Psychologists (pp. 249-270). Springer New York.

Reid, R.J., Coleman, K., Johnson, E. A., Fishman, P. A., Hsu, C-C., Soman, M. P., ...\& Larson, E. B. (2010). The group health medical home at year two: Cost savings, higher patient satisfaction, and less burnout for providers. Health Affairs (Millwood), 29(5), 835-43.

Reiger, D.A., Goldberg, I.D., \& Taube, C.A. (1978). The de facto US mental health services system: A public health perspective. Archives of General Psychiatry, (5), 685-693.

Richard, A. A., \& Shea, K. (2011). Delineation of self-care and associated concepts. Journal of Nursing Scholarship, 43(3), 255-264.

Roberge, P., Hudon, C., Pavilanis, A., Beaulieu, M., Benoit, A., Brouillet, H., .. . Vanasse, A. (2016). A qualitative study of perceived needs and factors associated with the quality of care for common mental disorders in patients with chronic diseases: The perspective of primary care clinicians and patients. BMC Family Practice, 17, 1-14. 
Robson, C. (2011). Real world research: a resource for users of social research methods in applied settings. Chichester: Wiley.

Ruddy, N.B., Borresen, D.A., \& Gunn, W.B. (2008). The collaborative psychotherapist: Creating reciprocal relationships with medical professionals. Washington, D.C.: American Psychological Association.

Runyan, C. N. (2011). Psychology can be indispensable to health care reform and the patientcentered medical home. Psychological Services, 8(2), 53-68.

Rural Health Information Hub. (2017, June 26). West Virginia rural healthcare facilities. Rural Health Info. Retrieved from https://www.ruralhealthinfo.org/states/west-virginia

Salci, M. A., Schlindwein Meirelles, B. H., \& Vieira da Silva, D., \& Guerreiro, M. (2017). Primary care for diabetes mellitus patients from the perspective of the care model for chronic conditions. Revista Latino-Americana De Enfermagem (RLAE), 25, 1-8.

Sandler, E. (2009). Behavioral health versus mental health. Does what we call it influence how people think about it? Psychology Today. Retrieved from https://www.psychologytoday.com/blog/promoting-hope-preventingsuicide/200910/behavioral-health-versus-mental-health

Schulman-Green, D., Jaser, S., Martin, F., Alonzo, A., Grey, M., McCorkle, R., ...\& Whittemore, R. (2012). Processes of self-management in chronic illness. Journal of Nursing Scholarship, 44(2), 136-144.

Sharpe, M., Walker, J., Hansen, C. H., Martin, P., Symeonides, S., Gourley, C., ...\& Murray, G. (2014). Integrated collaborative care for comorbid major depression in patients with 
cancer (SMaRT Oncology-2): A multicenter randomised controlled effectiveness trial. The Lancet, 384(9948), 1099-1108.

Shields, M. C., Patel, P. H., Manning, M., \& Sacks, L. (2011). A model for integrating independent physicians into accountable care organizations. Health Affairs, 30(1), 161172.

Stellefson, M., Dipnarine, K., \& Stopka, C. (2013). Peer reviewed: The Chronic Care Model and diabetes management in US primary care settings: A systematic review. Preventing Chronic Disease, 10,120180. doi: 10.5888/pcd10.120180

Strauss, A., \& Corbin, J. M. (1990). Basics of qualitative research: Grounded theory procedures and techniques. Thousand Oaks, CA: Sage Publications, Inc.

Suri, H. (2011). Purposeful sampling in qualitative research synthesis. Qualitative Research Journal, 11(2), 63-75.

Tabachnick, B. G., \& Fidell, L. S. (2007). Using multivariate statistics (5th ed.). Boston, MA: Allyn and Bacon.

Thota, A. B., Sipe, T. A., Byard, G. J., Zometa, C. S., Hahn, R. A., McKnight-Eily, L. R., \& Williams, S. P. (2012). Collaborative care to improve the management of depressive disorders: A community guide systematic review and meta-analysis. American Journal of Preventive Medicine, 42(5), 525-538.

Turchi, R. M., Antonelli, R. C., Norwood, K. W., Adams, R. C., Brei, T. J., Burke, R. T., \& Sia, C. (2014). Patient and family-centered care coordination: A framework for integrating care for children and youth across multiple systems. Pediatrics, 133(5), e1451-e1460. 
U.S. Institute of Medicine. (2001). Health and Behavior: The interplay of biological, behavioral, and societal Influences. In Research, Practice, and Policy. Washington (DC): National Academies Press. Retrieved from https://www.ncbi.nlm.nih.gov/books/NBK43744/

Unützer, J., Schoenbaum, M., \& Harbin, H. (2011). Collaborative care for primary/co-morbid mental disorders. Brief for CMS Meeting July 27, 2011 (updated August 4, 2011).

Retrieved from http://dhmh.maryland.gov/bhd/Documents/CMS_Brief_on_Collaborative_Care_4Aug11. pdf

van Dijk-de Vries et al. (2012). The ideal of biopsychosocial chronic care: How to make it real? A qualitative study among Dutch stakeholders. BMC Family Practice, 13-14. van Dongen, J.,Jean Jacques, Lenzen, S. A., van Bokhoven, M. A., Daniëls, R., van, d. W., \& Beurskens, A. (2016). Interprofessional collaboration regarding patients' care plans in primary care: A focus group study into influential factors. BMC Family Practice, 17, 5858.

Van Houtum, L., Rijken, M., Heijmans, M., \& Groenewegen, P. (2014, September 09). Patient-perceived self-management tasks and support needs of people with chronic illness: Generic or disease specific? Annals of Behavioral Medicine, 1-9.

Vassilev, I., Rogers, A., Blickem, C, Brooks, H., Kapadia, D., Kennedy, A. et al. (2013). Social networks, the 'work' and work force of chronic illness self-management: A survey analysis of personal communities. PLoS ONE 8(4), e59723.

doi:10.1371/journal.pone.0059723 
Von Korff, M., Scott, K.M., Gureje, O., (ed.) (2009). Global perspectives on mental-physical comorbidity in the WHO world mental health surveys. New York: Cambridge University Press.

Von Korff, M., Katon, W. J., Lin, E. H., Ciechanowski, P., Peterson, D., Ludman, E. J., \& Rutter, C. M. (2011). Functional outcomes of multi-condition collaborative care and successful ageing: Results of randomised trial. BMJ, 343, d6612. doi: 10.1136/bmj.d6612

Wagner, E.H., Austin, B.T. \& Von Korff, M. (1996). Organizing care for patients with chronic illness. Milbank Quarterly, 74, 511-544.

Walker, B. B. \& Collins, C. A. (2009). Developing an integrated primary care practice: Strategies, techniques, and a case illustration. Journal of Clinical Psychology, 65, 268280.

Ward, E. C., Clark, L. O., \& Heidrich, S. (2009). African American women’s beliefs, coping behaviors, and barriers to seeking mental health services. Qualitative Health Research, 19, 1589-1601.

Ward, B.W., Schiller, J.S., \& Goodman, R.A. (2014). Multiple chronic conditions among US adults: a 2012 update. Prevention of Chronic Disease, 11. E.62. DOI: http://dx.doi.org/10.5888/pcd11.130389.

Wells, K., Golding, J., \& Burnham, M. (1988). Psychiatric disorders in a sample of the general medical population with and without medical disorders. American Journal of Psychiatry, $145,976-981$.

West Virginia University. (2017). About us: Mission. Retrieved from https://about.wvu.edu/mission 
World Health Organization (WHO). (2016). Integrated care models: an overview. Retrieved from http://www.euro.who.int/_data/assets/pdf_file/0005/322475/Integrated-caremodels-overview.pdf

World Health Organization. (2017, June 26). Chronic disease and health promotion. Chronic Disease and Poverty. Retrieved from http://www.who.int/chp/chronic_disease_report/part2_ch2/en/

Wright, K. (2005). Researching internet-based populations: advantages and disadvantages of online survey research, online questionnaire authoring software packages, and web survey services, Journal of Computer-Mediated Communication, 10, (3). Retrieved from: http://onlinelibrary.wiley.com/doi/10.1111/j.1083-6101.2005.tb00259.x/full

Yuen, E., Gerdes, J., \& Waldfogel, S. (1999). Linkages between primary care physicians and mental health specialists. Families, Systems and Health, 17, 285-308. 


\section{Appendix A: Recruitment Script}

This is a letter intended to recruit participants for a research project to explore the relationship between primary care physician's endorsement of the biopsychosocial theory and collaboration with psychologists. This project is being conducted by Nicole O'Barto Trainer, doctoral candidate in the WVU counseling psychology program, with the supervision of Dr. Margaret Glenn, an associate professor in the College of Education and Human Services, Department of Counseling, Rehabilitation Counseling, and Counseling Psychology.

Participation in this online project will take approximately 10 minutes. Participants will be asked to complete a series of demographic questions, questions about the biopsychosocial theory and questions about collaboration with psychologists. The results of this doctoral dissertation research will be important in furthering understanding of ways to optimize collaboration to improve patient care. Results will be disseminated at national scholarly meetings and published in a peer-reviewed journal.

Participant involvement in this project will be kept as confidential as legally possible.

Participants may skip any question that they do not wish to answer and may discontinue at any time. All data will be reported in the aggregate. Participants must be 18 years of age or older and a licensed physician. Participation is completely voluntary and participants will not be asked any information that should lead back to their identity as a participant. West Virginia University's Institutional Review Board acknowledgement of this project is on file.

Title: An Exploratory Correlational Study of the Relationship Between Primary Care Physicians Endorsement of the Biopsychosocial Theory and Collaboration with Psychologists 
Abstract: The Chronic Care Model (CCM) is an evidenced based healthcare management system that encompasses a multidimensional approach to healthcare for the treatment of patients with chronic conditions. A component of this model is collaborative care. The theoretical viewpoints of the biopsychosocial model are central to collaborative care and evidenced-based health care interventions. The intent of these interventions is to provide integrated patient-centered healthcare delivered by a multidisciplinary team of healthcare professionals. This collaboration among providers in the interest of holistic patient-centered care is also the focus of today's efforts in health care reform. The purpose of this study is to determine the relationship between primary care physician's endorsement of biopsychosocial principles and the facilitation of mental health care for their patients with chronic illnesses.

Questions regarding this project can be directed to Dr. Margaret Glenn, Dissertation Committee Chair at 304-293-2276; Margaret.Glenn@mail.wvu.edu or Nicole O’Barto Trainer at 304-381-2211; nobarto@mix.wvu.edu.

Researcher: Nicole O'Barto Trainer

Study Population: West Virginia Primary Care Physicians

Participant Obligation: Complete a 10-minute online survey. Location: Online-West Virginia

Study runs: March 15, 2017 - April 15, 2017

http://wvu.qualtrics.com/SE/?SID=SV_cYn1y91Dp7g3EcR 


\section{Appendix B: Email Invitation to Participate}

Dear Participant,

This letter is a request for you to take part in an online research project to explore the relationship between primary care physician's endorsement of the biopsychosocial theory and collaboration with psychologists. This project is being conducted by Nicole O'Barto Trainer, doctoral candidate, in the WVU counseling psychology program, with the supervision of Dr. Margaret Glenn, an associate professor in the College of Education and Human Services, Department of Counseling, Rehabilitation Counseling, and Counseling Psychology. Your participation in this project is greatly appreciated and will take approximately 10 minutes to fill out the attached questionnaire.

Your involvement in this project will be kept as confidential as legally possible. All data will be reported in the aggregate. You must be a physician in the state of West Virginia to participate. I will not ask any information that should lead back to your identity as a participant. Your participation is completely voluntary. You may skip any question that you do not wish to answer and you may discontinue at any time. The survey includes an option that will allow you to withdraw from the survey. If you choose this option, all responses from you will be discarded. I will not attempt to capture information that you do not voluntarily provide. The survey will be available on Qualtrics, a web-based survey, data collection and analysis tool. West Virginia University's Institutional Review Board acknowledgement of this project is on file.

I hope that you will participate in this research project, as it represents an area of the collaboration literature that is unstudied and the results may help to facilitate the development of collaborative relationships between psychologists and physicians in the interest of integrated patient-centered primary care. 
To participate in the survey, please click on the following link:

http://wvu.qualtrics.com/SE/?SID=SV_cYn1y91Dp7g3EcR

Thank you very much for your time. Should you have any questions about this letter or the research project, please feel free to contact Nicole O'Barto Trainer at (304) 381-2211 or by email at nobarto@mix.wvu.edu or Margaret Glenn, Ed.D., CRC, Dissertation Chair at 304-2932276.

Thank you,

Nicole O'Barto Trainer 


\section{Appendix C: Questionnaire}

Description of Questionnaire

The purpose of this questionnaire is to identify the relationship between primary care physicians' knowledge and attitudes regarding the biopsychosocial model and collaboration and referral with psychologists. For the purpose of this study, the following definition(s) are provided.

Biopsychosocial model is as a comprehensive and systematic perspective for understanding the person and the relationships of the system outside and inside the person that influences both health and illness (Engel, 1977; Nicassio \& Smith, 1995; Sperry, 1988).

Thank you in advance for your participation in the questionnaire. The study is being conducted by Nicole O’Barto Trainer, MS, doctoral candidate, Counseling Psychology, West Virginia University and is part of her research for her doctoral dissertation under the direction of Dr. Margaret Glenn, Ed.D. The study has been approved by the West Virginia University Institutional Review Board. Participation in the questionnaire typically takes 5 to 10 minutes and is strictly anonymous. All responses are treated as confidential, and in no case, will responses from individual participants be identified. All data will be pooled and published in aggregate form only. Participants should be aware that a secure server is being used for this questionnaire, the online survey platform is Qualtrics. Many individuals find participation in this type of study to be enjoyable and participation in this study may provide you the opportunity to clarify your own opinions on the implications of the biopsychosocial model for the patients you treat and collaboration with psychologists. Participation in this study is voluntary and you may withdraw from the study at any time without any penalty. If you choose to discontinue participation all your responses will be discarded. Survey research of this nature is considered to 
be of minimal risk to participants. However, there is a possibility of uncomfortable feelings. If participants have further questions about this study or wish to express concern, they may contact the principal investigator, Nicole OBarto Trainer at 724-961-9999 or nobarto@ mix.wvu.edu

\section{Demographic Questionnaire}

1. Introduction to the study

2. Consent

3. What is your sex?

4. What is your age in years?

5. How many years have you been in practice as a primary care physician?

6. What is your primary work setting?

7. What is your specialty?

8. What is your degree type?

9. What percentage of your day to day clinical work involves treating patients with chronic illnesses?

○ Less than $20 \%$

○ $20 \%-40 \%$

○ $40 \%-60 \%$

○ 60\%-80\%

○ more than $80 \%$

10. Are you aware of a psychologist practicing in your community?

11-12. In the past 6 months, have you referred a patient with a chronic illness to a psychologist?

○ Yes If yes, number of referrals

O No

13-14. Have you initiated informal collaboration about a patient that involves an unscheduled, unstructured meeting with a psychologist in the past 6 months?

O Yes If yes, number of informal collaborations

O No 
15-16. In the past 6 months have you engaged in formal collaboration that involves scheduled meetings with a psychologist to discuss pertinent aspects of a patient's care?

○ Yes

If yes, number of formal collaborations

○ No

17. Do you have a psychologist working on site at your clinic?

○ Yes

○ No

\section{Please indicate your level of agreement with the following items:}

19. Treatment compliance by patients with chronic illnesses is facilitated by physicians who use their role as "experts" to provide comfort and confidence to their patients.

Strongly Agree

O Agree

$\bigcirc$ Disagree

○ Strongly Disagree

20. The emotional tone of the physician-patient relationship is a significant factor in treating patients with chronic illnesses successfully.

○ Strongly Agree

○ Agree

$\circ$ Disagree

○ Strongly Disagree

21. The quality of the physician-patient relationship forms the basis for healing.

- Strongly Agree

- Agree

- Disagree

- Strongly Disagree

22. The physician's support of patient autonomy increases the likelihood the patient will maintain long term change.

○ Strongly Agree

- Agree

- Disagree

- Strongly Disagree 
23. Physicians can effectively make use of intuition in the treatment of patients with chronic illnesses.

- Strongly Agree

- Agree

- Disagree

○ Strongly Disagree

24. Sometimes it can be beneficial for a physician to express his or her own emotions to a patient.

- Strongly Agree

- Agree

- Disagree

- Strongly Disagree

25. A physician's self-awareness is a fundamental skill in expert clinical work.

- Strongly Agree

- Agree

- Disagree

○ Strongly Disagree

26. The physician should respect the patient's wishes about the role he or she would like in the decision making about their own treatment.

○ Strongly Agree

- Agree

- Disagree

- Strongly Disagree

27. Cultural differences related to the patient's role in the family are likely to influence how the patient understands and experiences a chronic illness.

○ Strongly Agree

- Agree

- Disagree

○ Strongly Disagree

28. Chronic illness cannot be understood apart from its cultural context.

○ Strongly Agree

- Agree

○ Disagree 
○ Strongly Disagree

29. Effective management of healthcare for patients with chronic illnesses requires psychological interventions.

- Strongly Agree

- Agree

- Disagree

○ Strongly Disagree

30. The successful treatment of patients with chronic illnesses requires the physicians to make a long-term commitment to the patient's family as well.

○ Strongly Agree

- Agree

- Disagree

- Strongly Disagree

31. If there is a discrepancy between the patient's personal interpretation of their illness and the physician's narrative, this may negatively impact treatment.

- Strongly Agree

- Agree

- Disagree

- Strongly Disagree

32. Patient's perspectives on their chronic illnesses are a critical component of self-management in healthcare.

- Strongly Agree

- Agree

- Disagree

○ Strongly Disagree

33. The patient's ideas and expectations about his or her illness form the basis for developing a mutually agreeable treatment plan with their physician.

- Strongly Agree

- Agree

- Disagree

○ Strongly Disagree

34. Physicians have the responsibility to help patients articulate their perspective of their illnesses. 
- Strongly Agree

- Agree

- Disagree

- Strongly Disagree

35. Facilitation of mental health treatment for patients with chronic illnesses can be impacted by the physicians understanding of psychological interventions.

- Strongly Agree

- Agree

- Disagree

○ Strongly Disagree

36. The quality of the physician-patient relationship is a determining factor in the facilitation of collaborative care.

○ Strongly Agree

- Agree

- Disagree

- Strongly Disagree

37. Addressing mental health issues related to chronic illness requires an efficient approach to coordination of care.

- Strongly Agree

- Agree

- Disagree

- Strongly Disagree

38. Primary care physicians play a crucial role in the provision of mental health for patients with chronic illness.

○ Strongly Agree

- Agree

- Disagree

- Strongly Disagree 


\section{Appendix D: Table 1}

Table 1

Frequencies and Percentages for the Categorical Variables

$\begin{array}{lll}\text { Variable } & N & \%\end{array}$

\section{Gender}

Male

40

Female

31

Total

71

100.0

Degree Type

M.D.

D.O.

Total

71

100.0

Percentage of day to day clinical work treating patients with chronic

illness

Less than $20 \%$

9

$20 \%-40 \%$

8

11.3

$40 \%-60 \%$

21

29.6

$60 \%-80 \%$

20

more than $80 \%$

13

18.3

Total

71

100.0

Primary care physicians aware of a psychologist practicing in their community 
Yes

No

I don't know

Total

Referred a patient with a chronic illness to a psychologist in the past 6

months

Yes

No

Total

71

100.0

Engaged in informal collaboration with a psychologist in the past 6

months

Yes

11

No

60

Total

71

100.0

Engaged in formal collaboration with a psychologist in the past 6

months

Yes

14

19.7

No

57

80.3

Total

71

100.0

Psychologist on staff

Yes

9

12.7

No

62

87.3

Total

71

100.0 


\section{Appendix E: Table 2}

Table 2

Mean, Standard Deviation, Minimum, and Maximum for the Continuous Variables $(N=71)$

\begin{tabular}{lcccc}
\hline \multicolumn{1}{c}{ Variable } & Minimum & Maximum & $M$ & SD \\
\hline Age & 24 & 69 & 49.79 & 12.93 \\
Years in practice as a primary care physician & 0 & 40 & 20.03 & 12.38 \\
Number of referrals for patients with chronic illness & 1 & 50 & 3.72 & 7.52 \\
Number of Informal Collaborations & 1 & 7 & 0.44 & 1.26 \\
Number of Formal Collaborations & 1 & 25 & 0.72 & 3.11 \\
\end{tabular}

